\title{
Poly(dimethylsiloxane)-poly(ethylene oxide)-heparin block copolymers II: Surface characterization and in vitro assessments
}

\author{
D.W. Grainger,* K. Knutson, and S. W. Kim ${ }^{\dagger}$ \\ Department of Pharmaceutics and Center for Controlled Chemical Delivery, University of Utah, \\ Salt Lake City, Utah 84112 \\ J. Feijen \\ Department of Chemical Technology, Biomaterials Section, Twente University of Technology, \\ P.O. Box 217, 7500 AE Enschede, The Netherlands
}

Amphiphilic block copolymers containing poly(dimethylsiloxane), poly(ethylene oxide), as well as heparin-coated glass beads and tubes were evaluated for the amounts and activities of surface-immobilized heparin. Because the amphiphilic copolymer system is thermodynanmcally predicted to demonstrate low-energy phase enrichment on the surfaces of aircast films, studies were also undertaken to understand the in vitro results. Solventcast copolymer films have a heterogeneous microphase-separated structure according to transmission electron micrographs. Wilhelmy plate contact angle analysis indicates significant surface restructuring occurs upon hydration. Attenuated total reflectance infrared spectroscopy studies of the desiccated and hydrated films at two different sampling depths show compositional heterogeneity as a function of depth, as well as near surface restructuring allowing surface enrichment of the high-energy segments following contact with water. Significant concentrations of heparin are detected on the surface of these coatings by toluidine blue assays. In addition, a portion of the surface-bound heparin maintains its original bioactivity as determined by recalcification times, thrombin times, and Factor Xa assays. These substrates were also tested for platelet adhesion and activation reactions in vitro using polymer-coated beads in rabbit platelet-rich plasma. Heparinized polymers promoted low levels of platelet adhesion and serotonin release. Surface concentrations of heparin from bioactivity assays were then correlated with platelet adhesion and the extent of platelet release to assess the efficacy of this heparin-immobilized copolymer as a blood-compatible material or coating.

\section{INTRODUCTION}

Since the major problems with blood-contacting biomaterials occur at the interface between blood and the implanted material, the research presently undertaken to improve the performance of these biomaterials has focused on the characterization of the implant interface and prevention of surfaceinduced thrombosis. One approach for improving blood compatibility of bio-

*Present address: Oregon Graduate Institute, Beaverton, OR 97006-1999.

${ }^{\dagger}$ To whom correspondence should be sent.

Journal of Biomedical Materials Research, Vol. 24, 403-431 (1990)

(C) 1990 John Wiley \& Sons, Inc. 
materials has been to immobilize anticoagulants, particularly heparin, at interfaces. Most attempts have followed one of the following strategies: ${ }^{1,2}$ 1) ionic binding of heparin onto the material surfaces, 2) covalent attachment of heparin onto or into the materials, or 3) chemical modification of the material surfaces to confer heparin-like properties.

Optimum efficacy from these approaches might be provided by heparinized materials which: 1) provide sustained, controlled release of heparin from the material surfaces at efficacious concentrations or maintain an effective surface-immobilized microenvironment to prevent surface-induced thrombosis, and 2) preserve the bioactivity of the bound, released, or immobilized heparin, particularly its ability to bind antithrombin III.

Recently, it has been shown that immobilized heparin's bioactivity is very sensitive to its mode of attachment. ${ }^{3-5}$ Efforts have been made to avoid utilizing certain functional groups on heparin and to use spacer chains to immobilize the heparin away from the surface into a more "bulk-like" environment.

Our most recent work to immobilize heparin onto materials has been the synthesis and characterization of amphiphilic block copolymers containing a hydrophobic block of poly(dimethylsiloxane) (PDMS), a hydrophilic block of poly(ethylene oxide) (PEO), and a heparin moiety. ${ }^{6}$ The goal of this strategy is to investigate both the effect of the hydrophilic-hydrophobic balance of the block copolymers and covalently bound heparin on interfacial responses with blood. Of particular interest are the phase-enrichment phenomena which, as thermodynamically driven processes, occur on surfaces of segmented and block copolymers in response to external environments. ${ }^{7-9}$ Surface characterization using contact angle, electron microscopy, and attenuated total reflectance infrared spectroscopy (ATR/FTIR) under both ambient and hydrated conditions was undertaken in order to provide a quantitative basis for explaining the interfacial phenomena observed for PDMS-PEO-heparin triblock copolymers in vitro. This paper presents the results of the surface characterization methods, various efforts to quantify the amounts and bioactivities of heparin on the surfaces of these copolymers, and an assessment of their utility as new blood-compatible materials.

\section{EXPERIMENTAL}

\section{Materials}

Block copolymers of PDMS-PEO-heparin and PDMS-PEO were synthesized and characterized as described previously ${ }^{6}$ and stored frozen in moisturesealed amber bottles. The synthesis, as shown in Figure 1, involved covalent coupling of semitelechelic amino-PDMS via a diisocyanate to diamino terminated PEO in solution. Heparin was then coupled to PDMS-PEO by either EDC-activation of carboxylic groups or reductive amination using $\mathrm{NaCNBH}_{3}$. 


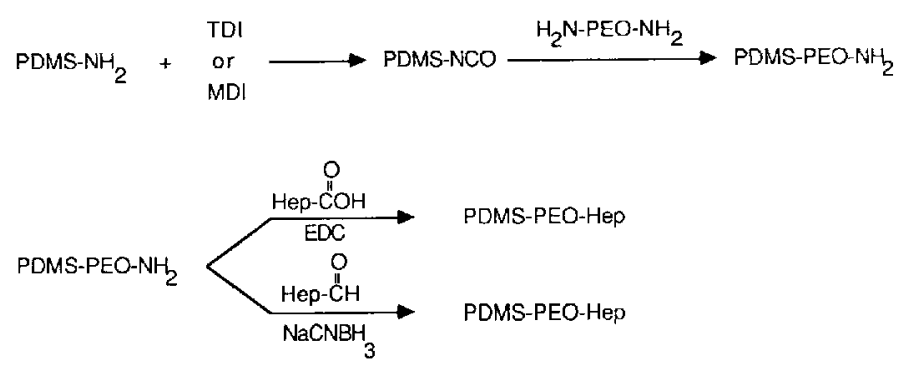

Figure 1. Synthetic outline for PDMS-PEO-heparin.

PDMS coatings for control samples were made from RTV 731 Silastic adhesive (Dow Corning, Midland, MI) or Silastic RTV adhesive (General Electric, Waterford, NY).

Heparin: Commercial heparin (Diosynth, Chicago, IL) with an activity of $176.4 \mathrm{IU} / \mathrm{mg}$ as determined by the manufacturer was used as supplied for heparin standards.

O-toluidine blue: A toluidine blue solution $(0.0015 \%)$ was obtained by adding solid o-toluidine blue (15 mg/L, Sigma Chemical, St. Louis, MO) and $2.0 \mathrm{~g} \mathrm{NaCl}$ to 1 liter $\mathrm{HCl}(0.01 \mathrm{~N})$.

Rabbit brain cephalin (1 lyophilized vial, Sigma Chemical, Taufkirchen, FRG) was diluted according to supplied instructions with $30 \mathrm{~mL}$ of an aqueous $\mathrm{NaCl}$ solution $(0.85 \%)$ and frozen in $3-\mathrm{mL}$ aliquots until used.

Thrombin (Thrombinair, Armour Pharmaceutical Co., Kankakee, IL, $1000 \mathrm{U} /$ vial) was diluted with sterile water to $10 \mathrm{U} / \mathrm{mL}$ and stored frozen.

Fresh platelet-rich (PRP) and platelet-poor plasmas (PPP) were prepared by collecting blood from male rabbits (New Zealand White, $2.5 \mathrm{~kg}$ ) via catheterized femoral artery exsanguination into plastic syringes containing $3.8 \%$ sodium citrate solution (final dilution $1: 9$ ). Blood was carefully transferred to Falcon tubes, centrifuged at $200 \mathrm{~g}$ for $10 \mathrm{~min}$ at $4^{\circ} \mathrm{C}$ and the PRP supernatant collected. The pellets were further centrifuged at $1500 \mathrm{~g}$ for $20 \mathrm{~min}$ at $4^{\circ} \mathrm{C}$, and PPP supernatant was mixed with the PRP to give a PRP with a final platelet concentration of $3 \times 10^{5} / \mu \mathrm{L}$. After mixing, platelets were equilibrated at room temperature for $60 \mathrm{~min}$ and used within $4 \mathrm{~h}$.

Antithrombin III (ATIII), S-2222, and Factor Xa (KabiVitrum, Molandal, Sweden) were reconstituted from lyophilized vials with sterile water per supplier's instructions (Helena Labs, Beaumont, TX) and stored frozen.

Glass beads (mean diameter $230 \mu \mathrm{m}$, Ferro Corp., Cataphote Division, Jackson, MS), glass coverslips (Corning, $24 \mathrm{~mm} \times 50 \mathrm{~mm}$ ) and test tubes ( $3.5 \mathrm{~mL}$ volume) were cleaned by soaking in chromic acid for $24 \mathrm{~h}$, washing alternately with ethanol and distilled water over $8 \mathrm{~h}$, and drying under vacuum at $50^{\circ} \mathrm{C}$. 


\section{Surface characterization}

Wilhelmy plate contact angle

Clean glass coverslips were coated with RTV PDMS (1\% w/v in tetrahydrofuran (THF)), cured at $50^{\circ} \mathrm{C}$ in vacuum, soaked in water for $12 \mathrm{~h}$, and then redried in vacuum. Plates were then coated in triplicate with PDMSPEO and PDMS-PEO-heparin (2\% w/v in THF) and vacuum dried at $40^{\circ} \mathrm{C}$. Following repeated water-soaking to remove leachables, plates were vacuum dried and analyzed for advancing and receding contact angles on a Wilhelmy balance (Wettech, Biomaterials International, Salt Lake City, UT) using a double-distilled water medium. Hydrated contact angles were measured after 1 and $12 \mathrm{~h}$ continuous immersion in double-distilled water.

\section{Transmission electron microscopy (TEM)}

Carbon-sputtered copper grids were coated with thin films of PDMSPEO-heparin $\left(0.5 \% \mathrm{w} / \mathrm{v}\right.$ in THF $\left.: \mathrm{H}_{2} \mathrm{O}\right)$ and air-dried overnight. Following vacuum drying at $22^{\circ} \mathrm{C}$, grids were exposed to the vapor of $\mathrm{RuO}_{4}(1 \%$ aqueous solution source) for $4 \mathrm{~h}$ at room temperature and immediately vacuum dried. Transmission electron micrographs were taken with a JEOL JEM $200 \mathrm{CX}$ instrument.

\section{Attenuated total reflectance infrared spectroscopy (ATR/FTIR)}

Spectra of PDMS-PEO-Hep block copolymers were obtained with a Digilab FTS $20 / 80$ spectrometer $\left(0.05 \mathrm{~cm}^{-1}\right.$ resolution, 1024 scans, MCT detector). Samples were prepared by ambiently casting films of commercial heparin (from distilled water), PEO (from THF), PDMS (from THF), PDMS-PEO (from THF), and PDMS-PEO-Hep (from THF : water) onto zinc selenide (ZnSe) and germanium $(\mathrm{Ge})$ internal reflection elements ( $45^{\circ}$ facecut angle) and vacuum desiccated at room temperature. The uncoated (reference) and coated internal reflection elements were aligned at $60^{\circ}$ in a Harrick $4 X$-beam condensing variable angle ATR cell and then analyzed. These same films were then completely immersed in freshly distilled water for various time and reanalyzed in varying states of hydration by ATR/FTIR. The hydrated spectra were compared to nonhydrated spectra following baseline flattening and absorbance subtraction of pure water spectra from the hydrated spectra.

\section{In vitro analysis}

Batches of cleaned glass beads and glass test tubes were coated with solutions $(1 \% \mathrm{w} / \mathrm{v}$ in THF or THF/water filtered through Teflon filters, pore size 
$0.5 \mu \mathrm{m}$ ) of RTV PDMS, PDMS-PEO-Hep block copolymers, and the unheparinized PDMS-PEO analogues. PEO-coated beads were prepared by using a triisocyanate (Colonate L, Nippon Polyurethane Industrial Ltd., Tokyo, Japan) as a cross-linking agent (end group ratio $1: 1$ ) in $2 \% \mathrm{w} / \mathrm{v}$ solutions of PEO in dimethylformamide (DMF). Curing at $60^{\circ} \mathrm{C}$ in vacuo produced a cross-linked, continuous film of "PEO" (a cross-linked PEO-based polyetherurethane) insoluble in water. Other coated beads and tubes were suction filtered, dried at $40^{\circ} \mathrm{C}$ under vacuum, and then soaked and rinsed four times with distilled water to remove unbound heparin and unreacted PEO from the copolymer matrix, or acetic acid generated from PDMS cross-linking. APTT assays were performed on the final rinse water to confirm that all soluble heparin had been removed. Half of the PDMS-coated tubes were then coated again with PDMS-PEO-heparin and PDMS-PEO copolymers and then subjected to the same rinsing and drying treatments. The beads were finally mechanically sieved (U.S. Standard \#40) to remove aggregates.

\section{Quantitation of surface-immobilized heparin on coated substrates}

\section{Recalcification times}

PDMS coatings formed homogeneous cross-linked films after $24 \mathrm{~h}$ vacuum curing. Coatings of all polymers on glass tubes were clear, intact, and continuous except for slight clouding of the PDMS substrates.

Glass- and PDMS-coated tubes were used as negative and positive controls, respectively, in recalcification determinations. The procedure involved incubation of $0.5 \mathrm{~mL}$ citrated fresh-frozen human plasma and $0.1 \mathrm{~mL}$ of a saline solution of cephalin in the tubes at $37^{\circ} \mathrm{C}$ for $1 \mathrm{~min}$ followed by the addition of $0.05 \mathrm{~mL}$ of $0.2 \mathrm{M} \mathrm{CaCl}_{2}$. The plasma solution was monitored for clotting by manually dipping a stainless-steel wire hook into the solution to detect fibrin threads. Clotting times were recorded at the first signs of fibrin formation on the hook. Complete clots typically followed within a minute after fibrin was first detected. Cephalin, a phospholipid, was used in the assay to supplement plasma phospholipids required in the intrinsically activated coagulation pathway. Excess amounts of phospholipids served to accelerate fibrin formation and enhance the clotting endpoint once the coagulation cascade was activated by exposure to a foreign surface. This improved endpoint detection and reproducibility of the assay.

\section{Toluidine blue assay}

Surface-immobilized heparin was quantified by the procedure of Smith and coworkers ${ }^{11}$ with slight modifications to accommodate coated beads. Seven tubes, each containing $2.0 \mathrm{~mL}$ of the toluidine blue solution and $0.01 \mathrm{~mL}$ of the various heparin standard solutions $(4$ to $14 \mu \mathrm{g} / \mathrm{mL}$ in $0.2 \%$ $\mathrm{NaCl}$ ), were vortexed for $30 \mathrm{~s}$. Blanks utilizing $0.01 \mathrm{~mL} 0.2 \% \mathrm{NaCl}$ instead 
of the heparin solutions were made analogously. Bead blanks were obtained by vortexing $100 \mathrm{mg}$ of clean glass beads in $2 \mathrm{~mL}$ of the toluidine blue solution for $30 \mathrm{~s}$. Copolymer-coated beads in quantities of $50-300 \mathrm{mg}$ were also vortexed with $2 \mathrm{~mL}$ toluidine blue for $30 \mathrm{~s}$. Both bead systems, heparin standards, and blanks were then vortexed with $5 \mathrm{~mL}$ hexane to adsorb dye-bound heparin not immobilized on the coated surfaces to the hexane: water interface. The aqueous layers were finally monitored for UV absorbance at $631 \mathrm{~nm}$ (Perkin-Elmer Lambda UV/Vis 7 spectrophotometer) within $15 \mathrm{~min}$.

\section{Thrombin times}

Inhibition of thrombin generation by heparinized surfaces was compared to heparin standards by the procedure of Sirridge and Shannon ${ }^{12}$ modified to monitor coated beads. Beads coated with cross-linked PDMS, PDMSPEO-Hep block copolymers and PDMS-PEO unheparinized copolymer analogs (20-50 mg) were weighed into Fibrosystem Fibrocups and incubated for $10 \mathrm{~min}$ at $37^{\circ} \mathrm{C}$ with PPP $(0.1 \mathrm{~mL})$. Thrombin $(0.1 \mathrm{~mL}, 10 \mathrm{U} / \mathrm{mL})$ was added and clotting times measured on a Fibrosystem Fibrometer. These results were compared to results from heparinized plasma standards $(0.05-$ $0.25 \mathrm{U} / \mathrm{mL})$.

\section{Factor Xa assay}

Surface-immobilized heparin was analyzed for bioactivity by a chromogenic assay by the method of Tein and coworkers ${ }^{13,14}$ modified to evaluate coated beads. Heparin standards in Tris buffer $\left(\mathrm{pH} 8.4,25^{\circ} \mathrm{C}\right)$ were made in a range of $0.1-0.6 \mathrm{U} / \mathrm{mL}$. A 6-point standard curve was constructed by averaging the results of five samples of each concentration evaluated by the following procedure:

Heparin standards $(0.1 \mathrm{~mL})$ were diluted in Falcon tubes with $0.1 \mathrm{~mL}$ ATIII and $0.8 \mathrm{~mL}$ buffer. Aliquots of this solution $(0.2 \mathrm{~mL})$ were incubated at $37^{\circ} \mathrm{C}$ for $3 \mathrm{~min}$ and Factor $\mathrm{Xa}(0.1 \mathrm{~mL}$, room temperature) was added and incubated an additional $30 \mathrm{~s} . \mathrm{S}-2222\left(0.1 \mathrm{~mL}, 2 \mathrm{mM}, 37^{\circ} \mathrm{C}\right)$ was then added and incubated at $37^{\circ} \mathrm{C}$ for $3 \mathrm{~min}$. The reaction was then terminated by adding $0.3 \mathrm{~mL}$ of $20 \%$ acetic acid and mixing. Samples were monitored spectrophotometrically at $405 \mathrm{~nm}$ using a Perkin-Elmer Lambda UV/Vis 7 spectrophotometer against water blanks.

Coated bead samples of cross-linked PDMS, unheparinized PDMSPEO, and PDMS-PEO-Heparin copolymers were assayed by the following procedure:

Various amounts of each type of bead $(5,10$, and $20 \mathrm{mg}$ ) were weighed into Falcon tubes in sets of six. Each sample was then incubated for $3 \mathrm{~min}$ 
with $0.2 \mathrm{~mL}$ ATIII and $0.18 \mathrm{~mL}$ buffer at $37^{\circ} \mathrm{C}$ with occasional shaking to promote wetting. Factor Xa, S-2222, and acetic acid were then added over the same time course and in identical quantities as for the heparin standards. Aliquots were monitored for absorbance at $405 \mathrm{~nm}$ and compared to the heparin standard curve.

\section{Platelet adhesion}

Quantities of coated beads $(700 \mathrm{mg}$ ) were carefully weighed into plastic disposable $3-\mathrm{cm}^{3}$ syringes and equilibrated with $2 \mathrm{~mL}$ PBS buffer $(\mathrm{pH}=$ 7.4) overnight prior to platelet adhesion studies. Buffer was squeezed out and $0.5 \mathrm{~mL}$ PRP introduced via another syringe. The syringes were tapped to remove air bubbles. They were then sealed with parafilm and rotated through a water bath at $37^{\circ} \mathrm{C}$ so that the beads were constantly falling through the PRP. Sets of syringes were arranged for adhesion time intervals of $15,30,45$, and $60 \mathrm{~min}$ of PRP incubation. At each time point, the syringes were quickly removed from the rotating bath, emptied into Falcon tubes and counted immediately with the Coulter Counter. A control sample of PRP incubated without beads was used as a reference for each time point. After depletion measurements, the beads were immersed in an isoosmotic fixative containing glutaraldehyde and paraformaldehyde in buffer for $12 \mathrm{~h}$. Following rinsing with distilled water, the beads were then freeze-dried and observed under scanning electron microscopy (JEOL JSM 35).

\section{${ }^{14} \mathrm{C}$-Serotonin Release}

${ }^{14} \mathrm{C}$-labeled 5-hydroxytryptamine $\left({ }^{14} \mathrm{C}-5 \mathrm{HT}\right)$ was obtained from Amersham $\left(0.1 \mu \mathrm{Ci}, 10^{-9} \mathrm{M}\right)$ and loaded into platelets in PRP by incubation at $37^{\circ} \mathrm{C}$ for 30 min according to a published method. ${ }^{15,16}$ Aliquots of PRP were aggregated with ADP, thrombin, and collagen to represent $100 \%$ release. Untreated PRP represented background or $0 \%$ release. Platelets centrifuged at $1500 \mathrm{~g}$ for $10 \mathrm{~min}$ demonstrated little additional release above background. The same procedure used for platelet adhesion experiments was used for 5 -HT release analysis with slight modifications. Only $15-$ and 30 -min incubation periods were utilized. The syringe contents were emptied after these incubations into Falcon tubes in an ice-bath. PRP samples $(0.05 \mathrm{~mL})$ were removed and the tubes quickly centrifuged at $1500 \mathrm{~g}$ for $5 \mathrm{~min}$ at $4^{\circ} \mathrm{C}$ to inhibit ${ }^{14} \mathrm{C}-5 \mathrm{HT}$ re-uptake. Aliquots $(0.01 \mathrm{~mL})$ of the resulting PPP supernatant showed no platelet populations and were counted together with the PRP samples in a Beckman scintillation counter to quantify ${ }^{14} \mathrm{C}-5 \mathrm{HT}$ release. 


\section{RESULTS AND DISCUSSION}

\section{Surface characterization}

Results for Wilhelmy Plate contact angle measurement on films of PDMS, PDMS-PEO and PDMS-PEO-Hep are shown in Table I. One striking result of the hysteresis comparisons is that, after the initial immersion in water, the heparinized copolymer advancing and receding contact angles differ by only $10^{\circ}$, displaying very little hysteresis compared to both PDMS and PDMS-PEO. Another interesting result is that, in all cases, extended hydration does not seem to affect advancing and receding angles, or hysteresis significantly after the initial wetting. One possible explanation is that, after immersion, water penetrates readily into PDMS-PEO and PDMS-PEO-Hep films (on the order of minutes) so that dry films quickly attain a hydrated state during Wilhelmy immersion.

The initial immersions (first advancing angle) for both PDMS-PEO and PDMS-PEO-Hep exhibit advancing angles nearly equal to that of pure PDMS, indicating that these surfaces in the dry state are very hydrophobic and probably rich in PDMS. These copolymer surfaces reorient rapidly under water during the first immersion so that the subsequent receding angles (first emersion) are substantially lower than PDMS (more hydrophilic). In addition, the subsequent advancing angles are dramatically reduced for PDMS-PEO and PDMS-PEO-Hep. One explanation for these nearly instantaneous reduced advancing angles in the amphiphilic block copolymers is that PDMS, originally exposed at the surface, buries itself under PEO domains upon exposure to water. This PDMS-rich overlayer reorients to mini-

TABLE I

Wilhelmy Plate Contact Angle Data for PDMS-PEO-Heparin in Water

\begin{tabular}{lcccc}
\hline \multicolumn{1}{c}{ Substrate $^{\mathrm{a}}$} & $\begin{array}{c}\text { Hydration Time } \\
(\mathrm{h})\end{array}$ & Adv. Angle & Rec. Angle & Hysteresis \\
\hline PDMS & 0 & $108.7 \pm 5.3$ & $79.5 \pm 1.6$ & 29 \\
& 1 & $103.5 \pm 2.6$ & $72.0 \pm 1.5$ & 30 \\
& 12 & $103.6 \pm 3.7$ & $71.4 \pm 1.1$ & 32 \\
PDMS-PEO & & & \\
& $0^{\mathrm{b}}$ & $100.0 \pm 4.5$ & $53.6 \pm 1.1$ & 46 \\
& $0^{\mathrm{c}}$ & $86.8 \pm 1.2$ & $53.6 \pm 1.1$ & 33 \\
PDMS-PEO-Hep & 1 & $88.7 \pm 2.1$ & $49.9 \pm 4.4$ & 40 \\
& 12 & $88.7 \pm 1.9$ & $53.5 \pm 1.4$ & 35 \\
& & & & \\
& $0^{\mathrm{b}}$ & $109.8 \pm 2.4$ & $45.8 \pm 1.8$ & 64 \\
& $0^{\mathrm{c}}$ & $56.2 \pm 1.2$ & $45.8 \pm 1.8$ & 10 \\
& 1 & $58.1 \pm 11.8$ & $48.5 \pm 1.5$ & 10 \\
& 12 & $58.7 \pm 1.9$ & $48.9 \pm 2.1$ & 10 \\
\hline
\end{tabular}

${ }^{\mathrm{a}} n=3, \pm$ S.D.

bFirst advancing angle.

'Subsequent advancing angles. 
mize interfacial tension by burying hydrophobic PDMS regions from the interface in order to expose hydrophilic PEO and heparin. In addition, the changes in advancing angles may reflect the time dependence of the Wilhelmy procedure (rate of film immersion and emersion).

PDMS-PEO may act as a surfactant analogue during wetting, forming a stable solid state quasimicellar structure with the PDMS blocks oriented toward the hydrophobic interior and water-saturated PEO covering the exterior in a swollen state in order to minimize interfacial energy. In PDMS-PEO-Hep, both PEO and heparin could act to stabilize PDMS in such a quasi-micellar state. In addition, PEO and heparin could reorganize on the water-swollen gel-like surface to limit the mobility of PDMS. All of these effects may act in unison within the block copolymers to reduce the advancing contact angles, prevent PDMS from resurfacing in air by restricting its mobility, and thus, demonstrate reduced hysteresis, particularly in the case of PDMS-PEO-Hep.

Previous swelling data ${ }^{6}$ suggest that these copolymers contain substantial amounts of water which would cause PDMS to require a stable position away from the penetrating water. A relatively hydrophobic region inside domains of PEO and heparin is feasible from a thermodynamic perspective and physically possible as shown by DSC data ${ }^{17}$ The $\mathrm{Si}-\mathrm{O}$ bonds in PDMS and the $\mathrm{C}-\mathrm{O}$ bonds in PEO and heparin are all very mobile, flexible linkages imparting the unique physical characteristics and structural rearrangements observed for these molecules. This permits hydrophobic PDMS to reorient during immersion and emersion, manifested as hysteresis. Timedependent changes upon hydration are minimal due to minimal water uptake by these PDMS films. Advancing angles for PDMS indicate its high hydrophobicity, as expected, at all hydration times.

Hysteresis for this substrate is rather large ${ }_{1}^{18,19}$ suggesting some degree of reorientation to minimize interfacial energetics with water. PDMS-PEO displays a larger hysteresis value at all degrees of hydration, suggesting greater interaction with water due to its hydrophilic component, possibly in the forms of swelling and water penetration throughout the matrix. Receding angles, indicative of the hydrophilic portion of a surface, demonstrate as anticipated that PDMS-PEO-Hep has greater hydrophilicity than either PDMS or PDMS-PEO. In addition, its low hysteresis suggests that water penetrates rapidly into the hydrophilic PDMS-PEO-Hep surface, creating a swollen gel-like matrix where PDMS may bury away from the surface. Even upon emersion, this structure may be sufficiently stabilized by the fully hydrated copolymer matrix to prevent PDMS from resurfacing in an air environment.

Figure 2 shows a transmission electron micrograph of PDMS-PEO-Hep stained with $\mathrm{RuO}_{4}$ vapor. Domains stained very dark are thought to be surface structures of PEO or heparin since ether linkages are oxidized rapidly by $\mathrm{RuO}_{4} \cdot{ }^{20}$ Also, the differences in electron density between PDMS and the other blocks provide an inherent phase contrast thought to be manifested as light gray regions of PDMS. Domains are scattered regions approximately $100 \AA$ in diameter (or length) interconnected by bridges of the same 


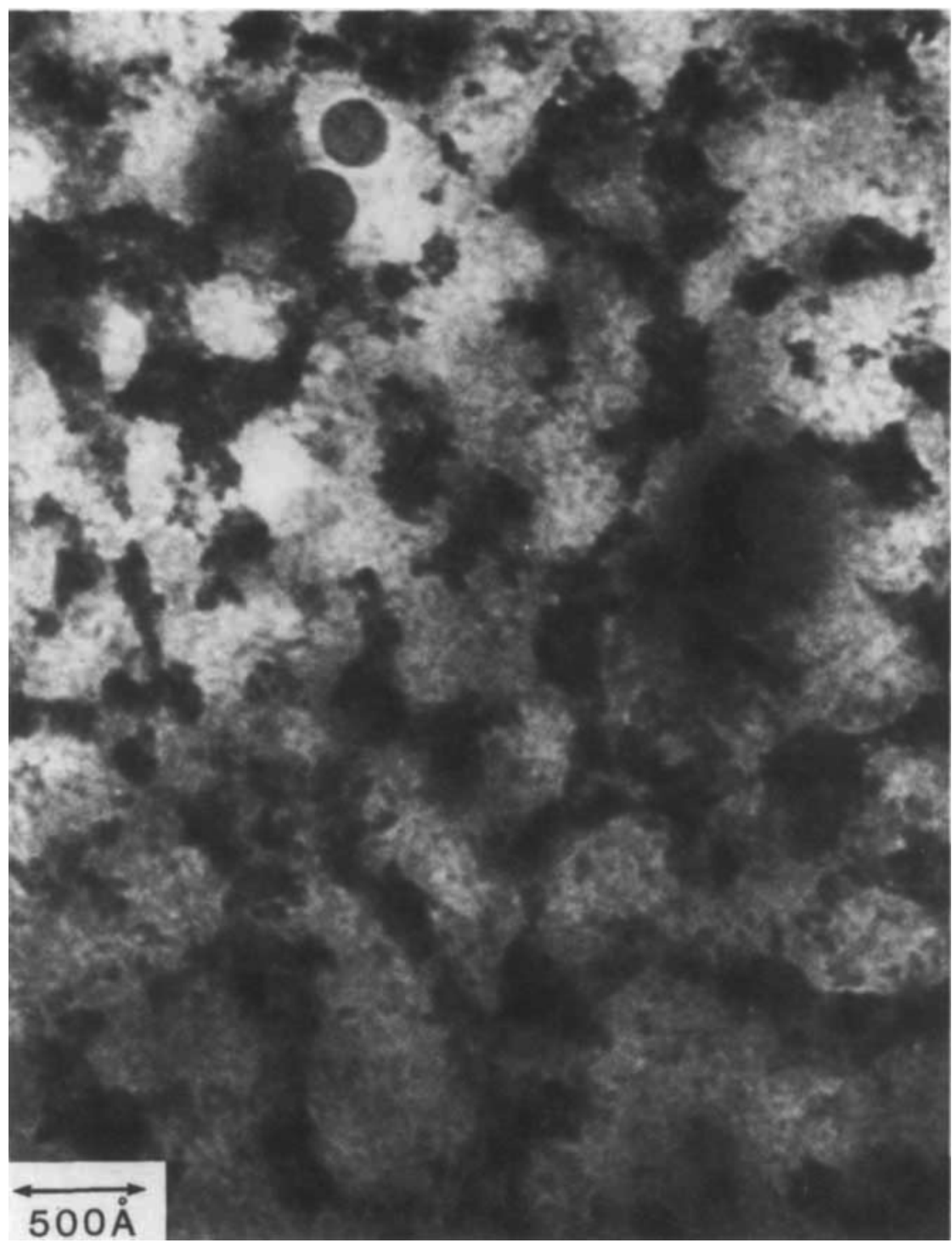

Figure 2. Transmission electron micrograph of PDMS-PEO-heparin thin films.

segment. This surface is representative of that cast into a hydrophobic air environment, and thus would be expected to demonstrate a surface enrichment of PDMS to minimize interfacial energy.

ATR/FTIR spectra of desiccated PDMS-PEO-Hep and control surfaces are illustrated in Figures 3 through 7. The refractive index of the zinc selenide ( $\mathrm{ZnSe}$ ) crystal was 2.42 and that of the germanium $(\mathrm{Ge})$ crystal was 4.0. The critical incident angles for the internal reflection elements with $45^{\circ}$ facecut 


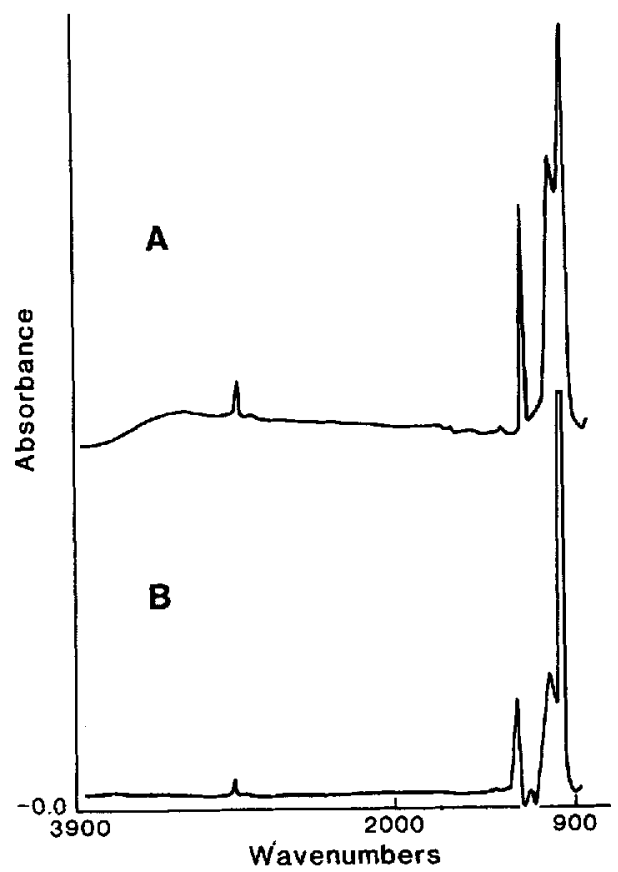

Figure 3. FTIR/ATR spectra for PDMS: (A) Ge internal reflection element (0-1.5 absorbance), (B) ZnSe internal reflection element (0.0-8.0 absorbance).

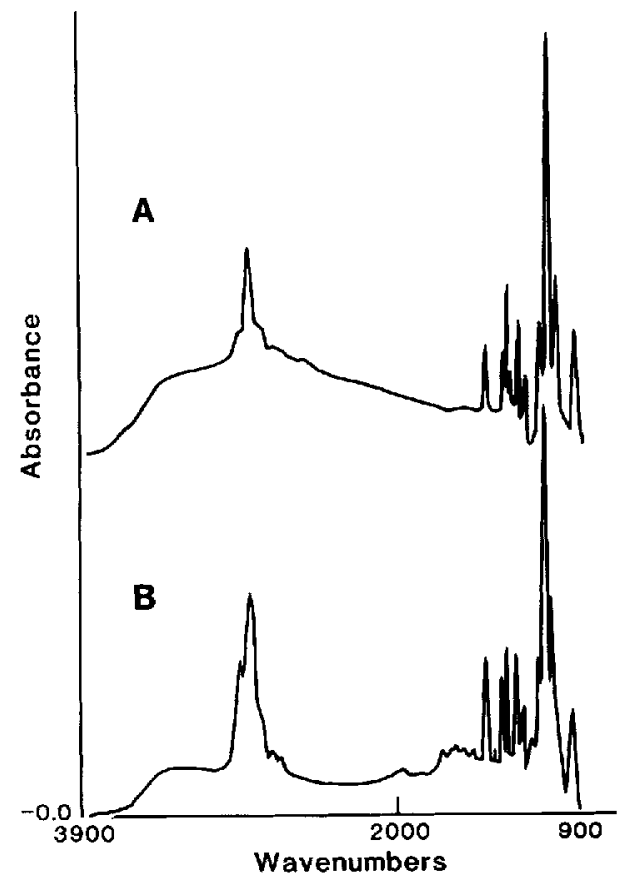

Figure 4. FTIR/ATR spectra for PEO: (A) Ge internal reflection element (02.0 absorbance), (B) ZnSe internal reflection element (0.0-1.3 absorbance). 


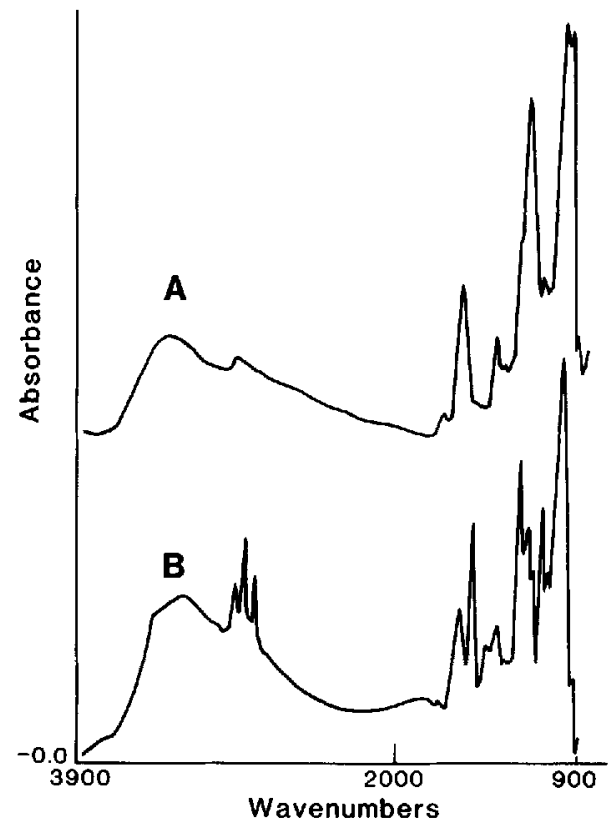

Figure 5. FTIR/ATR spectra for heparin: (A) Ge internal reflection element (0-1.6 absorbance), (B) ZnSe internal reflection element (0.0-0.2 absorbance).

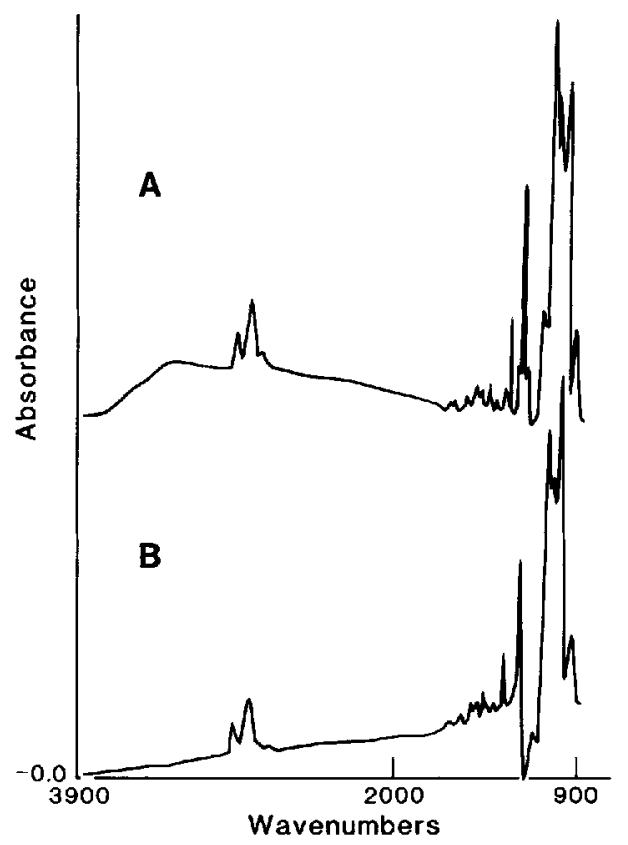

Figure 6. FTIR/ATR spectra for PDMS-PEO: (A) Ge internal reflection element (0-0.9 absorbance), (B) ZnSe internal reflection element (0.0-2.6 absorbance). 


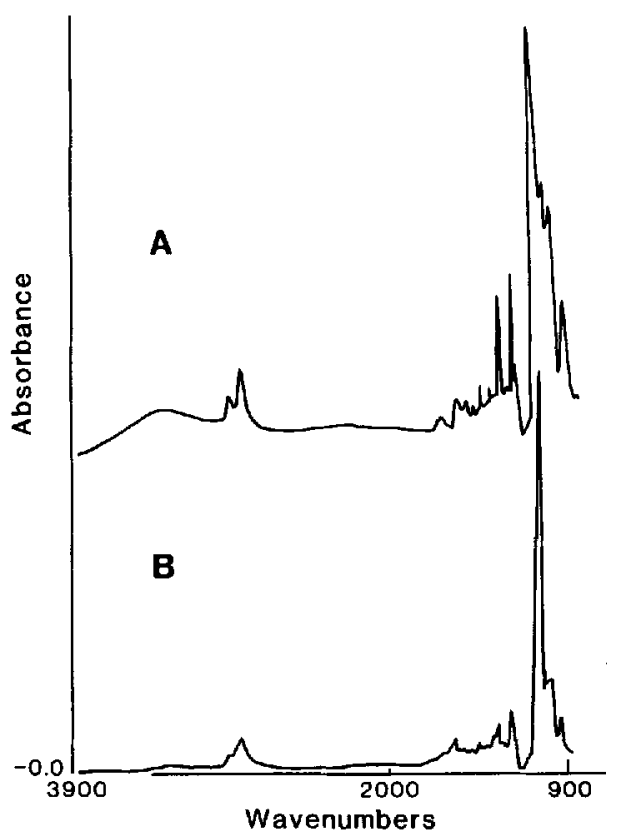

Figure 7. FTIR/ATR spectra for PDMS-PEO-heparin: (A) Ge internal reflection element (0-0.8 absorbance), (B) ZnSe internal reflection element $(0.0-$ 8.0 absorbance).

angles and aligned at $60^{\circ}$ are $48.7^{\circ}$ and $51.1^{\circ}$ for $\mathrm{Ge}$ and $\mathrm{ZnSe}$, respectively. ${ }^{10}$ The calculated sampling depths into the polymer surfaces are 1000 to $3000 \AA$ and 2000 to $8000 \AA$ from 4000 to $900 \mathrm{~cm}^{-1}$ when cast onto the Ge and ZnSe elements, respectively.

Figure 3 illustrates PDMS spectra for PDMS films cast onto the Ge internal reflection element (spectrum A) and $\mathrm{ZnSe}$ (spectrum B), respectively. Table II lists the vibrational modes associated with the major bands. The characteristic PDMS bands include $\mathrm{Si}-\mathrm{CH}_{3}$ symmetric deformation at $1259 \mathrm{~cm}^{-1}$ and $\mathrm{Si}-\mathrm{O}$ stretching near 1085 and $1014 \mathrm{~cm}^{-1}$.

$\mathrm{PEO}$ spectra of films cast onto $\mathrm{Ge}$ and $\mathrm{ZnSe}$ are illustrated in Figures $4 \mathrm{~A}$ and $4 B$, respectively. Vibrational modes assigned to major bands in the spectra are given in Table III. Characteristic bands of the polyether include the $1115-\mathrm{cm}^{-1} \mathrm{C}-\mathrm{O}-\mathrm{C}$ asymmetric stretching and the $1076-\mathrm{cm}^{-1} \mathrm{C}-\mathrm{O}-\mathrm{C}$ symmetric stretching.

Heparin films on Ge and $\mathrm{ZnSe}$ are shown in Figure $5 \mathrm{~A}$ and $5 \mathrm{~B}$, respectively. The band assignments are listed in Table IV. Heparin spectra include characteristic bands at $3287 \mathrm{~cm}^{-1}$ from overlapping $\mathrm{O}-\mathrm{H}$ and $\mathrm{N}-\mathrm{H}$ vibrations, $1735-\mathrm{cm}^{-1} \mathrm{C}=\mathrm{O}$ stretching, $1617-\mathrm{cm}^{-1}$ carboxylate $\mathrm{C}=\mathrm{O}$ stretching, $1146-\mathrm{cm}^{-1}$ cyclic ether (sugar ring) stretching and possibly $\mathrm{S}=\mathrm{O}$ stretching, and several lower wavenumber bands associated with $\mathrm{COOC}$ and $\mathrm{OS}=\mathrm{O}$ vibrations. 
TABLE II

Poly(dimethylsiloxane) Band Assignments

\begin{tabular}{cl}
\hline Wavenumber $\left(\mathrm{cm}^{-1}\right)$ & \multicolumn{1}{c}{ Vibrational Mode } \\
\hline 2963 & $\mathrm{CH}_{3} \mathrm{C}-\mathrm{H}$ asymmetric stretching \\
2906 & $\mathrm{CH} / \mathrm{C}-\mathrm{H}$ symmetric stretching \\
1415 & $\mathrm{C}-\mathrm{H}$ bending \\
1259 & $\mathrm{Si}-\mathrm{CH}_{3}$ symmetric stretching \\
1085 & $\mathrm{Si}-\mathrm{O}$ stretching \\
1014 & $\mathrm{Si}-\mathrm{O}$ stretching \\
\hline
\end{tabular}

PDMS-PEO diblock copolymer spectra are shown in Figure 6 on Ge (A) and $\mathrm{ZnSe}(\mathrm{B})$, while vibrational modes of characteristic bands are given in Table V. Absorbance ratios of spectral bands characteristic of individual blocks suggest enrichment of PDMS or PEO phases as a function of sampling depth. PDMS-PEO (Ge) spectra include $\mathrm{O}-\mathrm{H}$ stretching $\left(3316 \mathrm{~cm}^{-1}\right)$

TABLE III

Polyethylene Oxide Band Assignments

\begin{tabular}{cl}
\hline Wavenumber $\left(\mathrm{cm}^{-1}\right)$ & \multicolumn{1}{c}{ Vibrational Mode } \\
\hline 3344 & $\mathrm{O}-\mathrm{H}$ stretching \\
2886 & $\mathrm{CH}-\mathrm{C}-\mathrm{H}$ symmetric stretching \\
1473 & $\mathrm{C}-\mathrm{H}$ bending \\
$1356-1350$ & $\mathrm{CH}-\mathrm{O}$ stretching, $\mathrm{C}-\mathrm{H}$ deformations \\
1115 & $\mathrm{C}-\mathrm{O}-\mathrm{C}$ asymmetric stretching \\
1076 & $\mathrm{C}-\mathrm{O}-\mathrm{C}$ symmetric stretching \\
949 & $\mathrm{C}-\mathrm{H}$ deformations \\
\hline
\end{tabular}

TABLE IV

Heparin Band Assignments

\begin{tabular}{ll}
\hline Wavenumber $\left(\mathrm{cm}^{-1}\right)$ & \multicolumn{1}{c}{ Vibrational Mode } \\
\hline 3287 & $\mathrm{O}-\mathrm{H}, \mathrm{N}-\mathrm{H}$ stretching \\
2967 & $\mathrm{CH}_{3} \mathrm{C}-\mathrm{H}$ asymmetric stretching \\
2922 & $\mathrm{CH} \mathrm{C}-\mathrm{H}$ asymmetric stretching \\
2852 & $\mathrm{CH} \mathrm{C}-\mathrm{H}$ symmetric stretching \\
1735 & $\mathrm{COO} \mathrm{C}=\mathrm{O}$ stretching \\
1617 & $\mathrm{COO}$ asymmetric stretching \\
1539 & $\mathrm{~N}-\mathrm{H}$ bending, $\mathrm{C}-\mathrm{N}$ stretching \\
$1460-1428$ & $\mathrm{C}-\mathrm{H}$ deformations, $\mathrm{S}=\mathrm{O}$ stretching \\
1415 & $\mathrm{COO}$ carboxylate symmetric stretching \\
$1260-1200$ & $\mathrm{COOC}$ asymmetric stretching \\
& $\mathrm{C}-\mathrm{N}$ stretching, N-H bending \\
$1150-1100$ & $\mathrm{~S}=\mathrm{O}$ asymmetric stretching \\
1018 & $\mathrm{COOC}$ symmetric stretching \\
& $\mathrm{C}-\mathrm{O}-\mathrm{C}$ cyclic ether, $\mathrm{S}=\mathrm{O}$ stretching \\
& $\mathrm{C}-\mathrm{O}$ symmetric stretching \\
& $\mathrm{SOO}$ stretching \\
\hline
\end{tabular}


TABLE V

PDMS-PEO Block Copolymer Band Assignments

\begin{tabular}{cl}
\hline Wavenumber $\left(\mathrm{cm}^{-1}\right)$ & \multicolumn{1}{c}{ Vibrational Mode } \\
\hline 3316 & $\mathrm{~N}-\mathrm{H}, \mathrm{O}-\mathrm{H}$ stretching \\
2964 & $\mathrm{CH} / \mathrm{C}-\mathrm{H}$ asymmetric stretching \\
2884 & $\mathrm{CH}-\mathrm{C}-\mathrm{H}$ symmetric stretching \\
1680 & $\mathrm{C}=\mathrm{O}$ stretching urea Amide I \\
1548 & $\mathrm{~N}-\mathrm{H}$ bending, $\mathrm{C}-\mathrm{N}$ stretching \\
& urea Amide II \\
$1472-1430$ & $\mathrm{C}-\mathrm{H}$ deformations \\
1345 & $\mathrm{OCH}$ stretching \\
1263 & $\mathrm{Si}-\mathrm{CH}_{3}$ symmetric deformation \\
1101 & $\mathrm{COC}$ asymmetric stretching \\
1065 & $\mathrm{COC}$ symmetric stretching \\
1026 & $\mathrm{Si}-\mathrm{O}$ stretching \\
960 & $\mathrm{C}-\mathrm{H}$ deformations \\
\hline
\end{tabular}

TABLE VI

PDMS-PEO-Hep Band Assignments

\begin{tabular}{ll}
\hline Wavenumbers $\left(\mathrm{cm}^{-1}\right)$ & \multicolumn{1}{c}{ Vibrational Mode } \\
\hline 3295 & $\mathrm{~N}-\mathrm{H}, \mathrm{O}-\mathrm{H}$ stretching \\
2961 & $\mathrm{CH}_{3} \mathrm{C}-\mathrm{H}$ asymmetric stretching \\
2887 & $\mathrm{CH}_{2} \mathrm{C}-\mathrm{H}$ symmetric stretching \\
1740 & $\mathrm{COO} \mathrm{C}=\mathrm{O}$ stretching \\
1672 & $\mathrm{C}=\mathrm{O}^{-}$stretching urea Amide $\mathrm{I}$ \\
1601 & $\mathrm{COO} \mathrm{C}=\mathrm{O}$ stretching \\
1545 & $\mathrm{~N}-\mathrm{H}$ bending, $\mathrm{C}-\mathrm{N}$ stretching \\
$1460-1430$ & urea Amide II \\
1415 & $\mathrm{C}-\mathrm{H}$ deformations \\
1343 & $\mathrm{COO}$ symmetric stretching \\
1307 & $\mathrm{OCH}$ stretching \\
1261 & $\mathrm{~S}=\mathrm{O}$ stretching \\
$1250-1150$ & $\mathrm{CH}-\mathrm{Si}$ deformation \\
& $\mathrm{COOC}$ stretching \\
1189 & $\mathrm{C}-\mathrm{N}$ stretching, $\mathrm{N}-\mathrm{H}$ bending \\
1106 & $\mathrm{~S}=\mathrm{O}$ stretching \\
1072 & $\mathrm{C}-\mathrm{O}-\mathrm{C}$ asymmetric stretching \\
& $\mathrm{C}-\mathrm{O}-\mathrm{C}$ symmetric stretching \\
& $\mathrm{S}=\mathrm{O}$ stretching \\
\hline
\end{tabular}

and $\mathrm{C}-\mathrm{O}-\mathrm{C}$ stretching $\left(1101 \mathrm{~cm}^{-1}\right)$ bands characteristic of PEO, as well as the $\mathrm{Si}-\mathrm{CH}_{3}$ symmetric deformation $\left(1263 \mathrm{~cm}^{-1}\right)$ and $\mathrm{Si}-\mathrm{O}$ stretching bands $\left(1026 \mathrm{~cm}^{-1}\right)$ characteristic of PDMS. Coupling of the semitelechelic amino-PDMS via a diisocyanate to the diamino terminated PEO is confirmed by the urethane and urea linkages resulting in the weak band near $1680 \mathrm{~cm}^{-1}\left(\mathrm{C}=\mathrm{O}\right.$ stretching; urea Amide I) and the $1548-\mathrm{cm}^{-1}$ band $(\mathrm{C}-\mathrm{N}$ stretching and $\mathrm{N}-\mathrm{H}$ bending; Amide II). 
Absorbance ratios of the intense PEO $\mathrm{C}-\mathrm{O}-\mathrm{C}$ stretching band at $1101 \mathrm{~cm}^{-1}$ to the PDMS Si- $-\mathrm{CH}_{3}$ stretching band at $1263 \mathrm{~cm}^{-1}$ or to the PDMS Si-O band at $1026 \mathrm{~cm}^{-1}$ are greater for the Ge spectra (1.94 or 1.28 ratios) than for the $\mathrm{ZnSe}$ spectra (1.88 or 0.91 ratios). This suggests an enrichment of PEO within the near-surface sampling depths (1000-3000 $\AA$ ) as compared to the greater sampling depths (2000-8000 $\AA$ ). This is a different trend than observed with angle-dependent ESCA (ADESCA) and contact angle results. ${ }^{17}$ The difference may be explained by the near-surface sampling depths (greater than $1000 \AA$ ) as compared to the surface sampling depths (approximately $100 \AA$ ) of ADESCA and contact angles.

Desiccated PDMS-PEO-Hep spectra are illustrated in Figure 7 and band assignments listed in Table VI. Both spectra exhibit the salient features of $\mathrm{PEO}, \mathrm{PDMS}$, and heparin constituents. Dominant aliphatic $\mathrm{C}-\mathrm{O}-\mathrm{C}$ asymmetric stretching vibrations at $1106 \mathrm{~cm}^{-1}$ indicate PEO's presence. The $\mathrm{COO}^{-} \mathrm{C}=\mathrm{O}$ stretching band at $1415 \mathrm{~cm}^{-1}$ is characteristic of heparin. Broad weak bands absorbing between $1255-1150 \mathrm{~cm}^{-1}$ and $1020 \mathrm{~cm}^{-1}$ are sugges-

TABLE VII

Recalcification Times for PDMS-PEO-Heparin

\begin{tabular}{lcccc}
\hline \multicolumn{1}{c}{ Substrate } & PDMS M.W. & PEO M.W. & Heparin Method & $\begin{array}{c}\text { Clot Time } \\
(\mathrm{s})^{\mathrm{a}}\end{array}$ \\
\hline $\begin{array}{l}\text { Polymers on Glass } \\
\text { Glass }\end{array}$ & - & - & - & $149 \pm 11$ \\
PDMS-PEO1 & 9500 & 4000 & - & $461 \pm 45$ \\
PDMS-PEO2 & 9500 & 6000 & - & $676 \pm 46$ \\
PDMS-PEO1-Hep & 9500 & 4000 & EDC & $772 \pm 68$ \\
PDMS-PEO1-Hep & 9500 & 4000 & NaCNBH $_{3}$ & $744 \pm 79$ \\
& & & & \\
Polymers on PDMS & & - & - & $586 \pm 25$ \\
PDMS & Cross-linked & 4000 & - & $585 \pm 46$ \\
PDMS-PEO1 & 9500 & 6000 & - & $612 \pm 56$ \\
PDMS-PEO2 & 9500 & 4000 & EDC & $703 \pm 62$ \\
PDMS-PEO1-Hep & 9500 & 4000 & NaCNBH $_{3}$ & $744 \pm 79$ \\
PDMS-PEO1-Hep & 9500 & & &
\end{tabular}

${ }^{\mathrm{a}} n=8, \pm \mathrm{S} . \mathrm{D}$.

TABLE VIII

In Vitro Quantitation of Surface-Immobilized Heparin

Heparin Surface Concentration Method $^{\mathrm{a}}$

\begin{tabular}{lccc}
\cline { 2 - 4 } \multicolumn{1}{c}{ Substrate } & Tol. Blue $\left(\mathrm{g} / \mathrm{cm}^{2}\right)$ & Thrombin $\left(\mathrm{U} / \mathrm{cm}^{2}\right)$ & Factor Xa $\left(\mathrm{U} / \mathrm{cm}^{2}\right)$ \\
\hline PDMS & 0 & 0 & 0 \\
PDMS-PEO & 0 & 0 & $2.65 \times 10^{-3}$ \\
PDMS-PEO-Heparin & 0.55 & $2.65 \times 10^{-2}$ & $2.66 \times 10^{-2}$ \\
\hline
\end{tabular}

${ }^{a}$ Average of 6 samples, assuming bead diameter of $230 \mathrm{~m}$ and bead density of $2.5 \mathrm{~g} / \mathrm{cm}^{3}$. 
tive of heparin and PDMS. The weak urea Amide I vibrations confirm the coupling between the PDMS and PEO.

Ratios of characteristic constituent bands within each spectrum demonstrate different segmental compositions for each sampling depth. For example, ratios of heparin's carboxylate band at $1601 \mathrm{~cm}^{-1}$ versus PDMS $\mathrm{Si}-\mathrm{CH}_{3}$ band at $1261 \mathrm{~cm}^{-1}$ suggest nearly twice the concentration of heparin (or half the amount of PDMS) present at the ZnSe sampling depth $(0.51$ ratio) than for the Ge sampling depth (0.17 ratio). Similar comparisons confirm increased PEO within the ZnSe sampling depth as compared to that of Ge. Therefore, the data suggest PDMS enrichment within the near-surface regions of the heterogeneous copolymers that are probed with $\mathrm{Ge}$ internal reflection elements, as well as an enrichment of PEO and heparin within the deeper sampling depths probed with the $\mathrm{ZnSe}$ internal reflection elements. This concurs with the data obtained using the more surface-sensitive ADESCA technique. ${ }^{17}$

Hydrated films of PDMS-PEO-Hep demonstrate that reorganization occurs within the sampling depths as compared to the desiccated spectra as a function of hydration time. Samples hydrated for $10 \mathrm{~min}$ were analyzed in a hydrated state following water subtraction as shown in Figures 8A and 8B. The PDMS-PEO-Hep spectrum within the near-surface sampling depths (Fig. 8A) has a more intense $\mathrm{O}-\mathrm{H}$ stretching band at $3420 \mathrm{~cm}^{-1}$ suggesting residual from water subtraction. A shoulder at $3207 \mathrm{~cm}^{-1}$, possibly associated with $\mathrm{N}-\mathrm{H}$ stretching or a carboxyl stretching overtone (both from heparin), increases with longer hydration times, suggesting increasing heparin concentrations within this sampling depth. Intensities of $\mathrm{CH}_{2} \mathrm{C}-\mathrm{H}$ stretching vibrations absorbing $2887 \mathrm{~cm}^{-1}$ decrease with increasing hydration times. The bands absorbing near $1350 \mathrm{~cm}^{-1}$ with a high wavenumber shoulder are also characteristic of $\mathrm{PEO}$ and have been assigned to $\mathrm{O}-\mathrm{CH}_{2}$ stretching vibrations. The high wavenumber shoulder decreases with increasing hydration times. Hydrated PDMS-PEO-Hep spectra obtained at greater sampling depths (Fig. 8B) are similar to the near-surface spectra. However, the $1361-\mathrm{cm}^{-1}$ and $1279-\mathrm{cm}^{-1}$ shoulders associated with $\mathrm{O}-\mathrm{CH}_{2}$ stretching and $\mathrm{Si}-\mathrm{CH}_{3}$ symmetric deformations change significantly with increasing hydration.

Figures 9A and 9B show PDMS-PEO-Hep spectra hydrated for $18 \mathrm{~h}$ after water substraction obtained with the Ge and $\mathrm{ZnSe}$ internal reflection elements, respectively. The near-surface spectrum (Fig. 9A) indicates the PDMS-PEO-Hep film experienced reorientation with hydration. First, the intensity of the $\mathrm{N}-\mathrm{H}$ stretching band $\left(3207 \mathrm{~cm}^{-1}\right)$ has increased dramatically, suggesting structural relaxations allowing alterations in hydrogen bonding or concentrations of heparin and urea linkages within the sampling depth. In addition, intensities of the PDMS methyl $\mathrm{C}-\mathrm{H}$ stretching bands absorbing near $2960 \mathrm{~cm}^{-1}$ have decreased, indicating a decrease of PDMS. An additional weak band is evident near $2364 \mathrm{~cm}^{-1}$ that may be associated with increased amounts protonated secondary and tertiary amines on heparin $\left(\mathrm{NH}_{2}{ }^{+}, \mathrm{NH}^{+}\right.$stretching) as hydration occurs further within the 


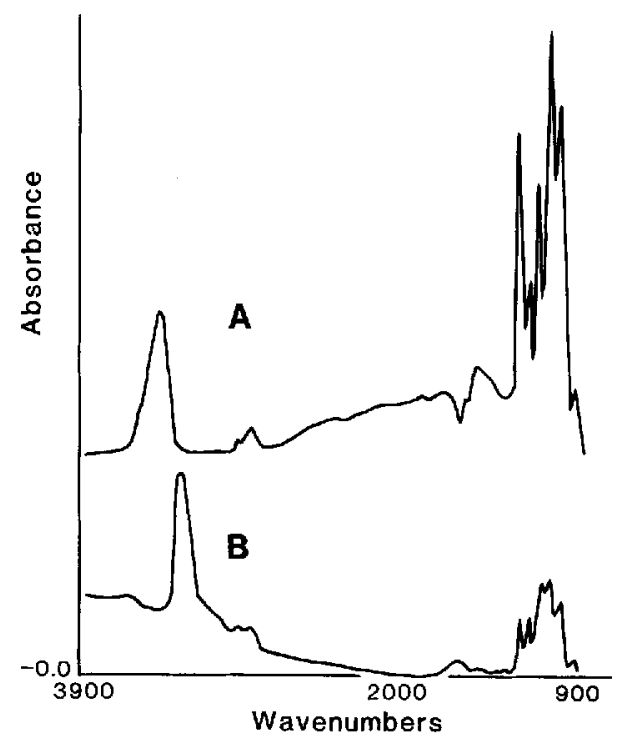

Figure 8. FTIR/ATR spectra for PDMS-PEO-heparin hydrated $10 \mathrm{~min}$ : (A) Ge internal reflection element (0-5.0 absorbance), (B) ZnSe internal reflection element (0.0-5.0 absorbance).

polymer. Bands characteristic of PDMS absorbing at $1263 \mathrm{~cm}^{-1}, 1097 \mathrm{~cm}^{-1}$, and $1024 \mathrm{~cm}^{-1}$ have decreased significantly in intensity. PEO and heparin associated bands near $1206 \mathrm{~cm}^{-1}$ and $1154 \mathrm{~cm}^{-1}$ have increased intensities.

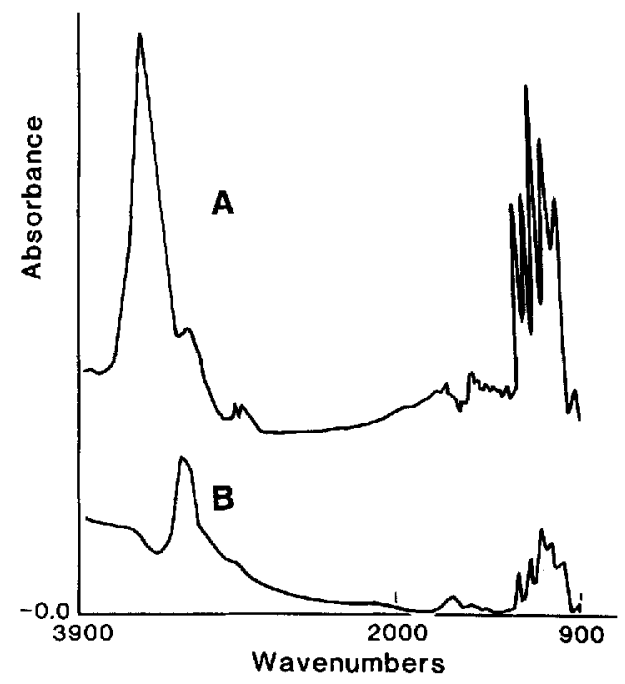

Figure 9. FTIR/ATR spectra for PDMS-PEO-heparin hydrated $18 \mathrm{~h}$ : (A) Ge internal reflection element (0-5.0 absorbance), (B) ZnSe internal reflection element $(0.0-5.0$ absorbance $)$. 
These observations support the hypothesis of near-surface restructuring with hydration, allowing increasing concentrations of hydrophilic segments near the surface. The ZnSe spectra (Fig. 9B) obtained following 18 h hydration demonstrate similar trends suggesting that hydration occurs within both sampling depths and results in similar restructuring at both depths.

\section{In vitro studies}

In all bioactivity studies, except recalcification times, only PDMS-PEOHep copolymers prepared by $\mathrm{NaCNBH}_{3}$ were used. Heparinized copolymers prepared by both EDC and $\mathrm{NaCNBH}_{3}$ methods show prolonged clotting times over their unheparinized analogues and the PDMS control surfaces as tested by recalcification times. Table VII lists respective clotting times for the polymer coatings on both glass and PDMS substrates. These data demonstrate extended clotting times for all polymers as compared to glass with the greatest prolongation caused by the heparinized substrates $(p<0.001$ for PDMS-PEO-Hep on glass compared to PDMS-PEO $(4000)$ on glass). Extended clotting times of cross-linked PDMS alone are consistent with findings of other researchers. ${ }^{21,22}$ No significant differences exist between the heparinized coatings on glass as compared to the heparinized coatings on PDMS. However, the heparinized coatings on PDMS exhibit significantly longer clotting times than their unheparinized analog on PDMS $(p<0.01$ for EDC-prepared heparinized copolymers versus PDMS$\mathrm{PEO}(4000)$ and $p<0.001$ for $\mathrm{NaCNBH}_{3}$-prepared heparinized copolymers versus PDMS-PEO(4000) on PDMS). In addition, artifacts may be partially induced by the coating procedure. Clear, bare glass surfaces may promote hydrophilic PEO and heparin blocks to coat preferentially onto hydrophilic glass, while PDMS substrates promote PDMS blocks to adhere. Thus, the other respective blocks may be forced to face out toward the air interface while curing, and subsequently face the plasma interface during bioassays. Because the bioactive effects of heparin were not as convincing as anticipated, other bioactivity assays were undertaken to attempt to distinguish heparinized and nonheparinized coating performance.

A linear relationship $\left(r^{2}=0.960\right)$ exists between the UV absorbance at $631 \mathrm{~nm}$ and the amounts of heparinized block copolymer-coated beads in the toluidine blue determinations. Blanks containing beads compared well with blanks containing only $0.2 \% \mathrm{NaCl}$, demonstrating that nonspecific dye-binding was minimal. Calculation of coated bead dye-binding correlated to the heparin standard curve indicates that the surface-immobilized heparin content of the coated beads was $41.5( \pm 14.8) \mu \mathrm{g}$ heparin per gram of beads or, assuming a bead diameter of $230 \mu \mathrm{m}$ and a reported glass bead density of $2.5 \mathrm{~g} / \mathrm{cm}^{3}, 0.55 \mu \mathrm{g} / \mathrm{cm}^{2}$ surface concentration.

In thrombin time measurements, $50 \mathrm{mg}$ of unheparinized PDMS- and PDMS-PEO-coated beads showed no prolongation of clotting times $(13 \pm$ $1.1 \mathrm{~s}$ ), while $50 \mathrm{mg}$ of heparinized copolymer beads prevented clotting in 
the Fibrocup in excess of $200 \mathrm{~s}$. Smaller quantities of heparinized beads $(20 \mathrm{mg})$ exhibited averaged clotting times of $46.73( \pm 7.3) \mathrm{s}$. This bioactivity corresponded to a heparin concentration of $0.33 \mathrm{U} / \mathrm{mL}$ if compared to the heparin standard curve. If compared to the actual amounts of heparin within each standard (by recalculating the standard curve in terms of amounts of heparin instead of concentrations), then $20 \mathrm{mg}$ of heparinized copolymer-coated beads represents $0.04 \mathrm{U}$ of heparin or, assuming a total $20-\mathrm{mg}$ surface area of $1.51 \mathrm{~cm}^{2}$, a heparin surface concentration of $2.65 \times$ $10^{-2} \mathrm{U} / \mathrm{cm}^{2}$.

Factor Xa results correlate well with thrombin time data. The method involves analyzing heparin as a bioactive complex of heparin and ATIII and its ability to bind and neutralize a known amount of Factor Xa. Unbound, excess Factor $\mathrm{Xa}$ then catalyzes the release of a chromogenic molecule, $p$-nitroanaline (pNA) from a substrate (Bz-Ile-Glu-Gly-Arg-pNA) and the amount of pNA detected photometrically is inversely proportional to the amount of bioactive heparin present. Unlike the toluidine blue assay which detects all heparin able to bind the dye, the Factor Xa assay detects only the heparin on the surface which is bioactive, forming complexes with both ATIII and Factor Xa.

In the Factor Xa analysis, the heparin standard curve for the chromogenic assay demonstrated reliable linearity $\left(r^{2}=0.970\right)$. Sample absorbances of less than 0.120 were assumed to deviate from this linearity and were discarded. For this reason, amounts of PDMS-PEO-Hep copolymer-coated beads in excess of $5 \mathrm{mg}$ showed heparin bioactivities giving absorbances in this range and could not be included in the assay. However, control beads coated with PDMS and PDMS-PEO were assayed in amounts up to $20 \mathrm{mg}$. PDMS beads showed absorbance corresponding to baseline levels of blank standards for all quantities of beads. PDMS-PEO copolymer beads $(20 \mathrm{mg})$ demonstrated absorbances corresponding to $0.004 \mathrm{U}$ of heparin $(2.65 \times$ $10^{-3} \mathrm{U} / \mathrm{cm}^{2}$ ), indicating some nonspecific absorption of Factor $X a$ to this coating. Smaller quantities of these beads, however, gave absorbances equivalent to the blanks. Heparinized block copolymer-coated beads $(5 \mathrm{mg})$ resulted in absorbances which when correlated to the standard curve, corresponded to $0.010 \mathrm{U}$ of heparin or $2.66 \times 10^{-2} \mathrm{U} / \mathrm{cm}^{2}$, nearly an order of magnitude greater than its unheparinized analogue. This measured surface concentration of heparin is nearly identical to concentrations determined by thrombin times.

Results of the in vitro bead bioactivity assays are summarized in Table VIII. Given the experimentally determined activity of the heparinized copolymer surface $\left(2.66 \times 10^{-2} \mathrm{U} / \mathrm{cm}^{2}\right)$ and the original activity of the immobilized heparin sodium salt $(165.4 \mathrm{U} / \mathrm{mg}),{ }^{6}$ the calculated amount of bioactive immobilized heparin is $0.16 \mu \mathrm{g} / \mathrm{cm}^{2}$. The toluidine blue assay which measures heparin, bioactive or not, indicates nearly 3.5 times this amount on the surface, implying that only one in three or four surface immobilized heparin molecules is bioactive. 
Depletion of platelets from PRP at $37^{\circ} \mathrm{C}$ was monitored on all polymeric coatings over time. Figure 10 shows the percent depletion of platelets from PRP at 15-, 30-, 45-, and 60-min intervals. Although previously published data for platelet adhesion and blood clottability on PDMS are inconsistent, ${ }^{21-26}$ cross-linked PEO-based polyether-urethane, PDMS, and PDMSPEO-Hep exhibit very low platelet adhesion compared to Biomer control surfaces. In addition, although no quantitative analysis was obtained, platelet aggregates in the bulk fluid phase were qualitatively noted from Coulter Counter distributions to increase over time for the cross-linked PEO-based polyetherurethane and Biomer systems and remain surprisingly low in both PDMS and PDMS-PEO-Hep systems. This suggests some polyurethane-specific aggregation activating mechanism that may be attributed to the urethane linkages.

Platelet adhesion in general appears to be a necessary precursor for subsequent platelet release and aggregation after surface activation ${ }^{21}$ Release of 5-HT via activation, however, does not necessarily have to correlate with platelet adhesion, as the release reaction does not appear to be an essential

Platelet Adhesion trom Rabbit PRP

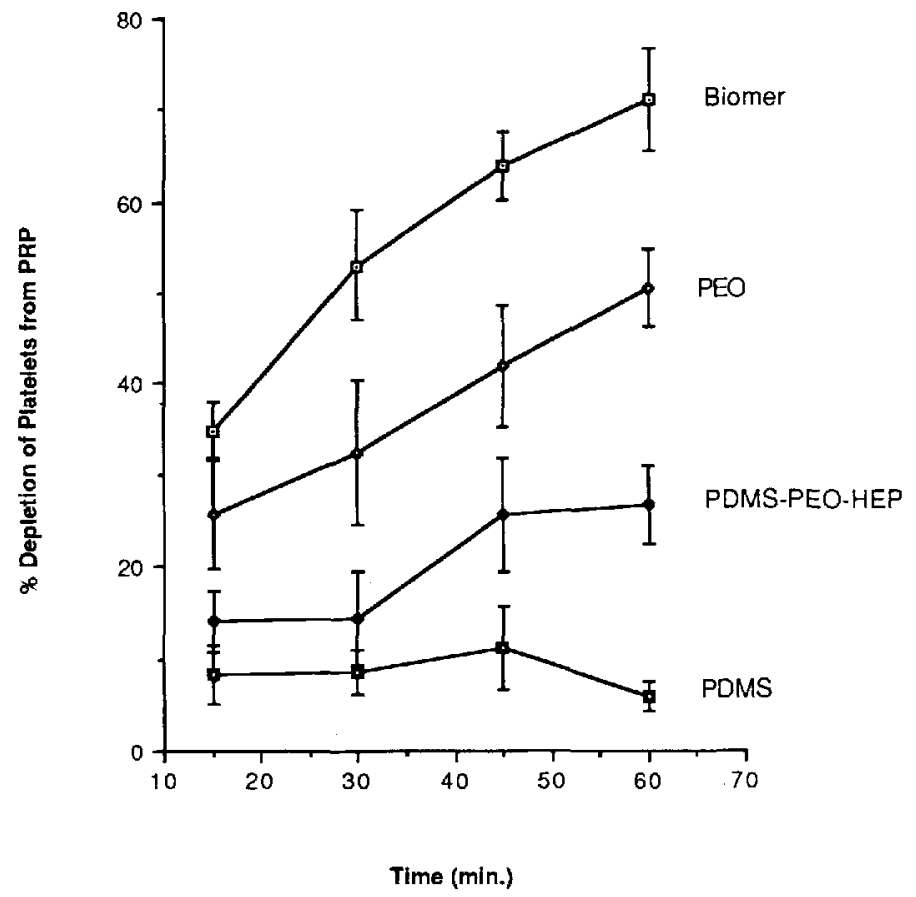

Figure 10. In vitro platelet adhesion to PDMS-PEO-heparin (PDMS $M_{\mathbf{n}}=$ 9500, PEO $M_{\mathrm{n}}=4000$, heparin $M_{\mathrm{n}}=10000$ ). 
prerequisite for platelet adhesion or platelet aggregation. Platelet activation as monitored by 5-HT release shown in Figure 11 demonstrates that the Biomer surface induces both high adhesion and severe release, while the heparinized copolymer and cross-linked homopolymers all demonstrate low levels of release. Comparison of data for PDMS-PEO-Hep system and controls suggests that there is a close correlation between platelet adhesion and release. Thus, it appears as though those platelets that do adhere are also those that activate to some extent in contact with the surface, releasing serotonin. In corroboration with others, ${ }^{27}$ materials which induce the most platelet release and activation (Biomer, cross-linked PEO-based polyetherurethane to lesser extent) were qualitatively noted in these studies to produce more bulk platelet aggregates (as measured by Coulter Counter counting distributions).

Re-uptake of released serotonin after platelet activation and degranulation is a legitimate concern. Active uptake suppression by rapid cooling in an ice bath is slow, compared to chemical ${ }^{28}$ or pharmacological methods ${ }^{29}$ and may result in quantification errors. However, other research ${ }^{30}$ compar- $^{-}$ ing imipramine-treated and untreated platelet release levels demonstrated only slight differences. Therefore, we felt justified in using cooling to prevent reuptake of serotonin. In addition, quantitative mass balances of serotonin levels inside platelets versus levels in plasma during release reactions

\section{Serotonin Release from PDMS-PEO-Heparin}

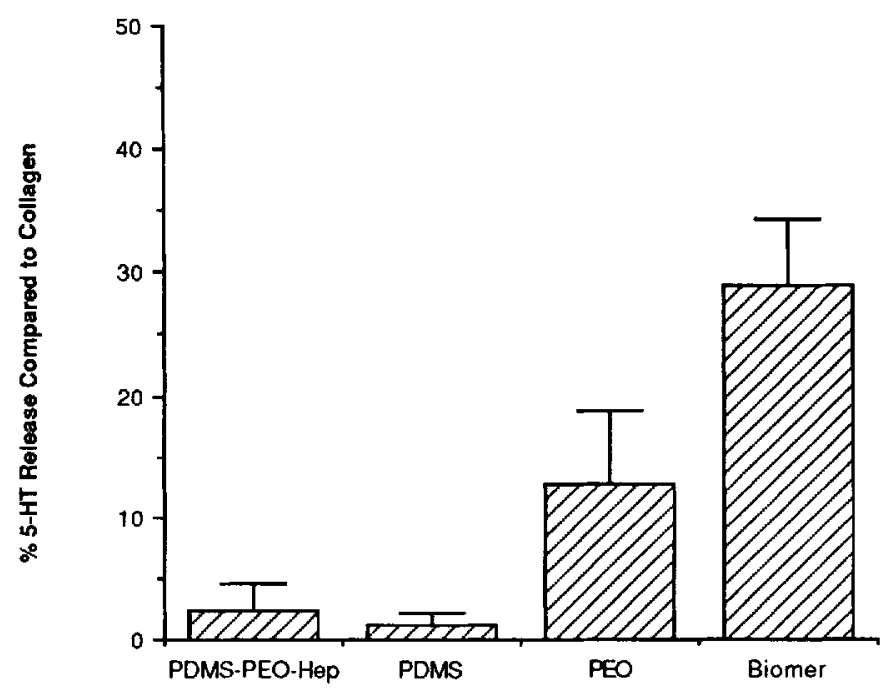

Polymeric Surfaces

Figure 11. In vitro ${ }^{14} \mathrm{C}$-serotonin release from platelets on PDMS-PEO-Hep $\left(\right.$ PDMS $M_{n}=9500$, PEO $M_{n}=4000$, heparin $M_{n}=10000$ ). 
have demonstrated a negligible rate of 5-HT reuptake by either adherent or bulk platelets after surface activation. ${ }^{31}$

Figures 12A-D show SEM micrographs of platelets attached to the test substrates. As expected, the PDMS beads (Fig. 12A) are virtually barefield after field showed no platelets at all. One explanation for these results would be that the surface was not wetting. Considering the buffer equilibration period, the ability of plasma proteins to promote wetting in PRP, and low levels of 5-HT release detected, the apparent PDMS passivity cannot be explained by a nonwetting surface. The PDMS-PEO-Hep-coated beads (Fig. 12B) show a few adherent platelets with varying degrees of activation. No aggregates are observed. This suggests that, compared to PDMS,

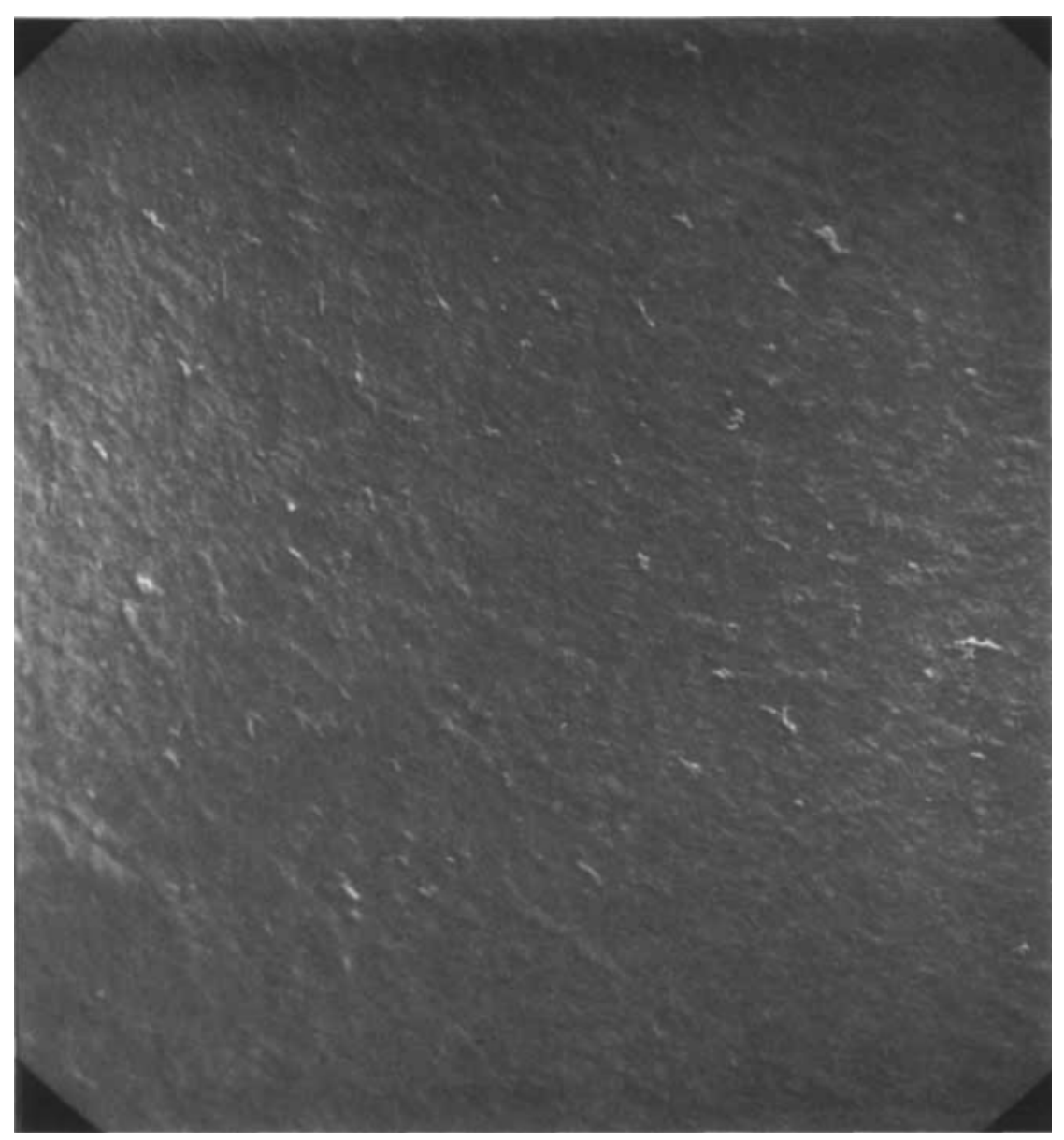

(a)

Figure 12. Scanning electron micrographs of adhered platelets (original magnifications) (a) PDMS ( $\times 400)$, (b) PDMS-PEO-Hep $(\times 3600)$, (c) PEO $(\times 1300)$, (d) Biomer $(\times 3600)$. 


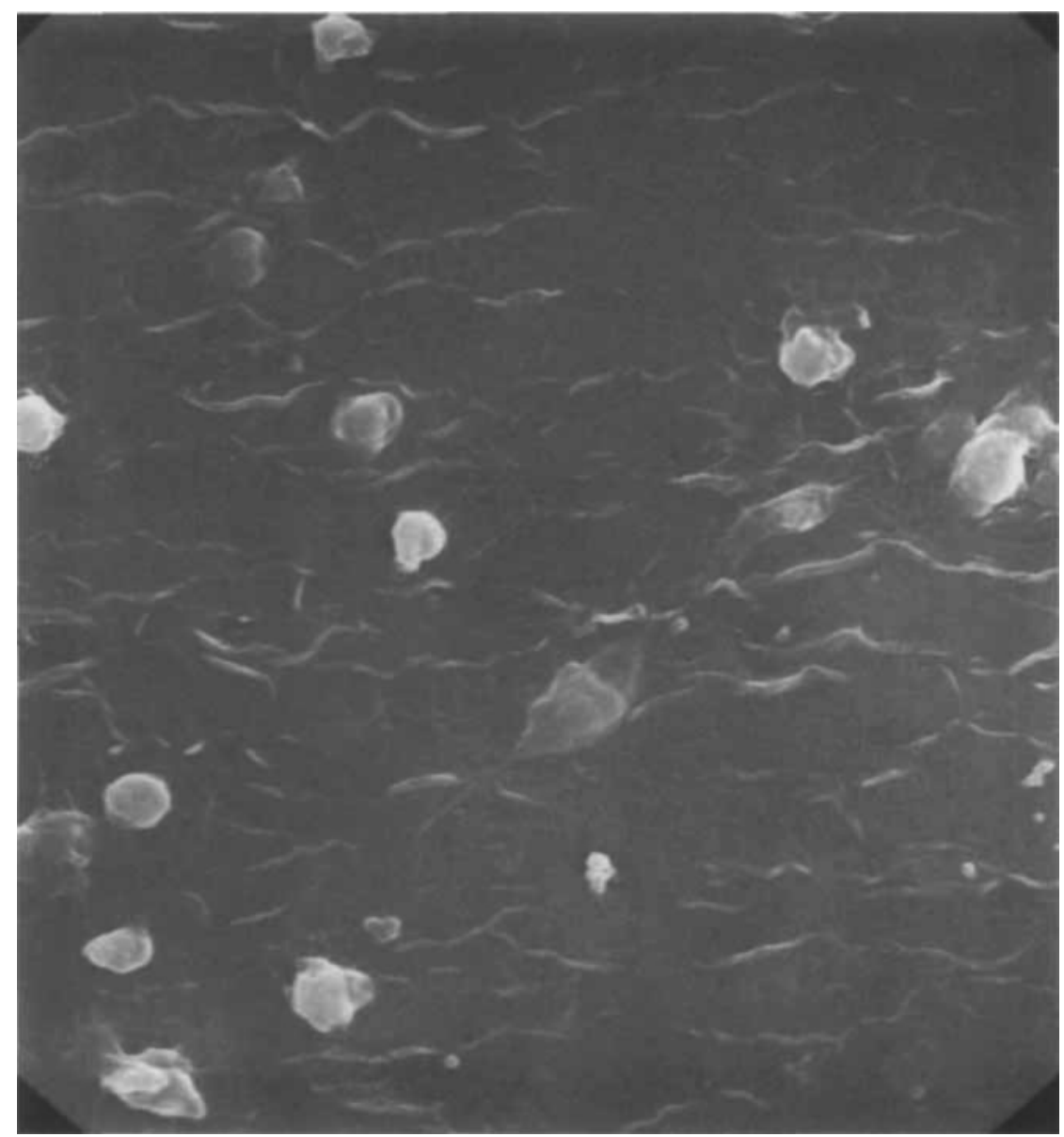

(b)

Figure 12. (continued)

the heparinized system, demonstrating higher degrees of activation and release, may be causing some heparin-induced platelet activation. ${ }^{32}$ In addition, it is interesting to note wrinkles in the underlying polymer film caused by SEM sample preparation-swelling in buffer and plasma followed by vacuum drying. Such swelling upon hydration presents a mobile, gel-like surface with an apparent increase in surface area. Hydrophilic surfaces, however, have been shown to decrease platelet adhesion, ${ }^{33-35}$ and may account for low platelet adhesion levels on this substrate. By contrast, the cross-linked PEO-based polyether-urethane surface (Fig. 12C) shows higher degrees of platelet adhesion, activation, pseudopodia extension, and aggregation, consistent with adhesion and release quantification. Some platelets have completely lost their morphology, indicating complete activation, while others are clumped into multiple platelet aggregates. Figure 12D shows 


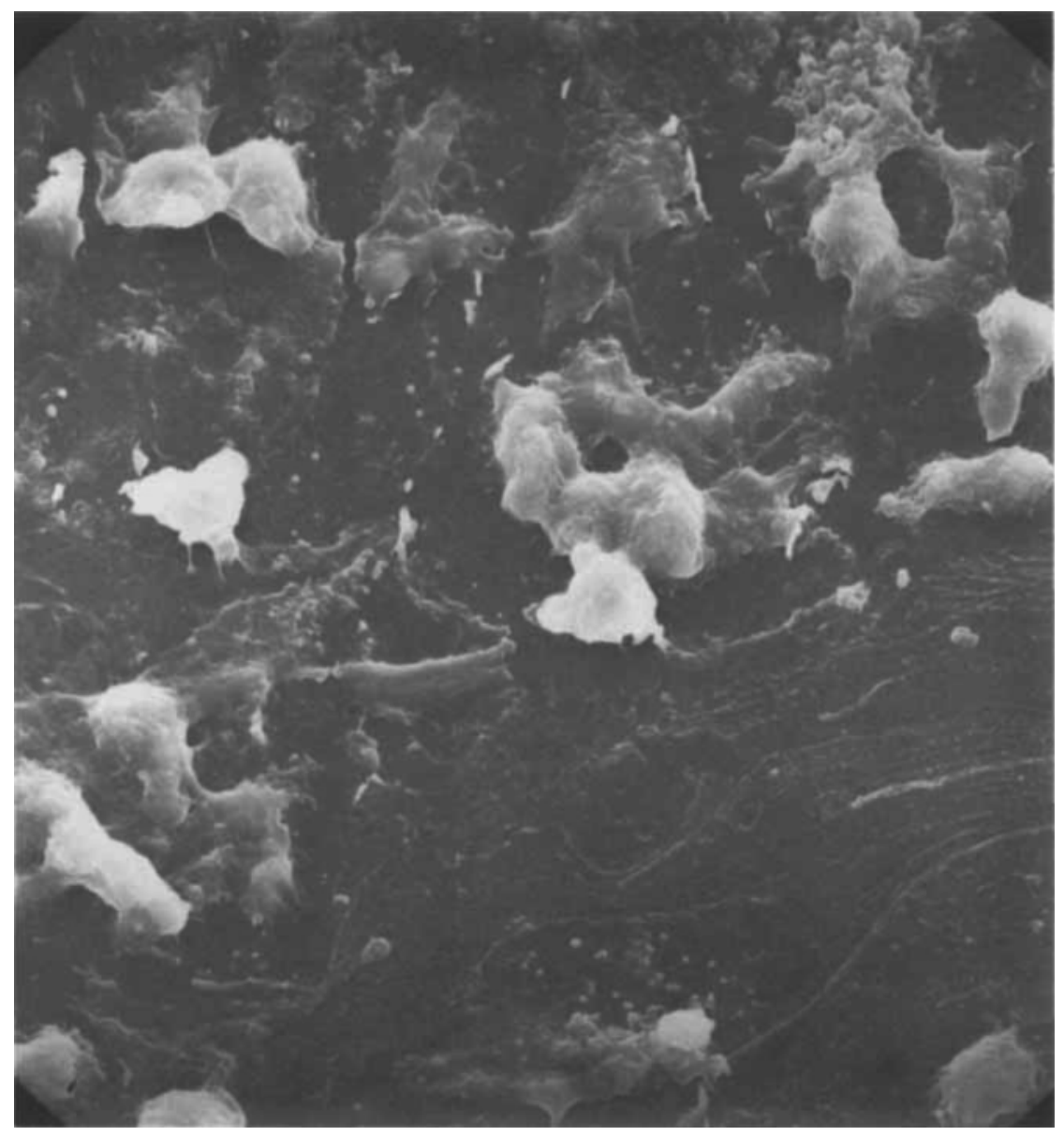

(c)

Figure 12. (continued)

platelets adhered onto a Biomer-coated bead. In this micrograph, platelets are maximally activated (flattened forms) with a possible second overlayer adhering on top of them. Pseudopodia and spreading are prevalent and a large majority of the surface is covered. This result is also consistent with Biomer's high degree of platelet adhesion and detected 5-HT release.

\section{CONCLUSIONS}

Surface characterization supports the ability of this block copolymer to change from ambient air to aqueous environments to present bioactive moieties toward plasma and also provides a fairly detailed picture of block copolymer chemistry and structure. Contact angle analysis suggests that these 


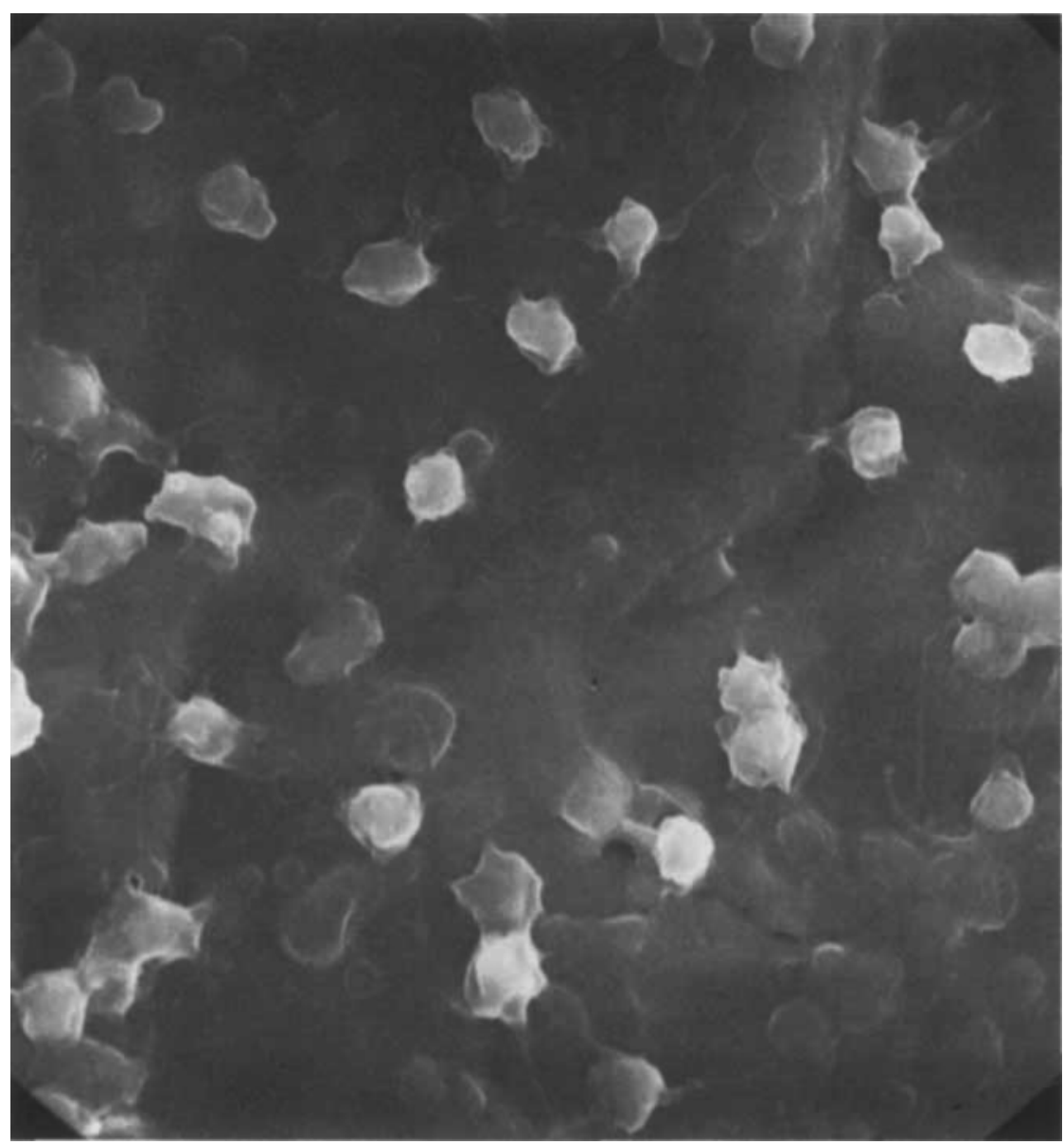

(d)

Figure 12. (continued)

surfaces are mobile and that the surface chemistry and structure - both in vacuum and in aqueous conditions - are different from the bulk chemistry and structure.

ATR/FTIR data confirm the presence of all three blocks (PEO, PDMS, and heparin) in the PDMS-PEO-Hep triblock copolymer at the two sampling depths in both desiccated and hydrated states. More importantly, this data, obtained at much deeper sampling depths than contact angle analysis, indicates segmental enrichment of PDMS in the near-surface regions and dramatic enrichment of PEO and heparin in the deeper regions when films are cast under air and desiccated. Heparin and PEO are present in the nearsurface regions, confirming the concept of PDMS phase enrichment but not a pure PDMS overlayer. With hydration, regions sampled by ATR demon- 
strate dramatic changes in structure and/or segment concentrations. The hydrophilic PEO and heparin segments enrich the near-surface areas.

Relaxation and reorientation occurs under aqueous conditions. Thus, the surfaces analyzed under low-energy air environments are probably not the surfaces that the platelets and blood proteins sense in an aqueous or blood medium. These differences are due to the amphiphilic nature of PDMSPEO-Hep copolymers thermodynamically driven to reorient under changing external conditions. Surface enrichment by the low-energy PDMS phases in air is probably reversed under water to expose PEO and heparin to aqueous and blood environments, stabilizing PDMS within the interior of intra-molecular quasi-micelle structures.

In vitro comparisons of PDMS-PEO-Hep copolymers with unheparinized analogues demonstrate a significant ability of the heparinized coating to neutralize clotting factors and prolong clotting times. Comparison of bioactivity data with direct quantitation of surface-immobilized heparin in the polymer indicates that although significant amounts of heparin are detected at the surface, only a fraction of these molecules are able to complex both ATIII and Factor Xa. It is likely that the coating technique traps or buries parts of many heparin molecules within the coating matrix, allowing more heparin to be detected than is actually bioactive. Platelet adhesion and release data suggest that PDMS-PEO-Hep and its homopolymer constituents react minimally with platelets in the test systems and seem to pacify surface activation compared to Biomer. This observation, combined with the effect of immobilized heparin on the surface to inactivate key coagulation factors, demonstrates the promise of this strategy for surface modification of existing hydrophobic biomaterial substrates or as a cross-linkable substrate itself.

The authors would like to thank Dr. T. Okano, Dr. C. Nojiri, and Dr. H. Jacobs for their technical assistance and helpful discussions, Dr. J. Andrade for providing the contact angle facility, and L. Naegle for typing this manuscript. The support of NIH grant HL17623-13, a Biomedical Research Fellowship from Twente University of Technology, Enschede, The Netherlands (DG), and an Advanced Predoctoral Graduate Fellowship in Pharmaceutics from the Pharmaceutical Manufacturers' Association (DG) are all gratefully acknowledged.

\section{References}

1. C. Fougnot, D. Labare, J. Jozefowicz, M. Jozefowicz, "Modifications to polymer surfaces to improve blood compatibility," in Macromolecular Biomaterials, G. Hastings, P. Ducheyne (eds.), CRC Press, Boca Raton, 1984, pp. 215-238.

2. S. W. Kim and J. Feijen, "Surface modification of polymers for improved blood compatibility," in CRC Critical Reviews in Biocompatibility, Vol. 1, Issue 3, CRC Press, Boca Raton, 1985, pp. 229-260.

3. I. Danishefsky and F. Siskovic, "Heparin derivatives prepared by modification of the uronic acid carboxyl groups," Thromb. Res., 1, 173-182 (1972). 
4. C. D. Ebert, E. S. Lee, J. Denneris, and S. W. Kim, "The anticoagulant activity of derivatized and immobilized heparins," in Advances in Chemistry Series 199: Biomaterials: Interfacial Phenomena and Applications, S. L. Cooper, N. A. Peppas (eds.), ACS Press, Washington, D.C., 1982, pp. 161-176.

5. A. Agarwal and I. Danishefsky, "Requirement of free carboxyl groups for the anticoagulant activity of heparin," Thromb. Res., 42, 673-680 (1986).

6. D. Grainger, S.W. Kim, and J. Feijen, "Poly(dimethylsiloxane)-poly (ethylene oxide)-heparin block copolymers I: Synthesis and characterization," J. Biomed. Mater. Res., 22, 231-249 (1988).

7. S.C. Yoon and B. D. Ratner, "Surface structure of segmented poly(etherurethanes) and poly(etherurethaneureas) with various perflourinated chain extenders: An x-ray photoelectron spectroscopic investigation," Macromol., 19, 1068-1079 (1986).

8. R. L. Schmitt, J. A. Gardella, Jr., J. H. Magill, L. Salvati, Jr., and R. L. Chin, "A study of surface composition and morphology of block copolymers of bisphenyl A polycarbonate and poly(dimethylsiloxane) by $x$-ray photoelectron spectroscopy (XPS or ESCA) and ion-scattering spectroscopy," Macromol., 18, 2675-2679 (1986).

9. G. L. Grobe, J. A. Gardella, Jr., W. L. Hopson, W. P. McKenna, and E. M. Eyring, "Angular-dependent ESCA and infrared studies of segmented polyurethanes," J. Biomed. Mater. Res., 21, 211-229 (1987).

10. K. Knutson and D. J. Lyman, "Surface infrared spectroscopy," in Surface and Interfacial Aspects of Biomedical Polymers, Vol. 1: Surface Chemistry and Physics, J. Andrade (ed.), Plenum Press, New York, 1985, pp. 197247.

11. P. K. Smith, A. K. Mallia, and G. T. Harmanson, "Colorimetric method for the assay of heparin content in immobilized heparin preparations," Anal. Biochem., 109, 466-473 (1980).

12. M.S. Sirridge and R. Shannon, "Evaluation of thrombin formation," in Laboratory Evaluation of Hemostasis and Thrombosis, 3rd ed., Lea \& Febiger, 1983, p. 161.

13. A. N. Tien, M. Lie, and U. Abdgaard, "Assay of heparin in plasma using a chromogenic substrate," Thromb. Res., 8, 413-416 (1976).

14. A. N. Tien and M. Lie, "Evaluation of an amidolytic heparin assay method: Increased sensitivity of adding purified antithrombin III," Thromb. Res., 10, 399-410 (1977).

15. H. Holmsen, A.C. Ostvold, and H. J. Day, "Behavior of endogenous and newly absorbed serotonin in the platelet release reaction," Biochem. Pharmacol., 22, 2599-2608 (1973).

16. D. Weber, W. K. Nichols, and S. F. Mohammad, "Effect of Heparin on Platelet Aggregation Inhibited by $\mathrm{PGI}_{2}$, Trifluoperazine, and Verapamil," Thromb. Res., 42, 477-487 (1986).

17. D. Grainger, J. Feijen, T. Okano, S. W. Kim, Y. K. Sung, D. Castner, and B. D. Ratner, "Poly(dimethylsiloxane)-poly(ethylene oxide)heparin block copolymers III: Surface and bulk compositional differences," J. Biomed. Mater. Res., 24, to appear (1990).

18. I. Vulic', unpublished evidence, Twente University of Technology, The Netherlands, 1987.

19. J.D. Andrade, L. Smith, D. E. Gregonis, "Contact angle and interface energetics," in Surface and Interfacial Aspects of Biomedical Polymers, Vol. 1: Surface Chemistry and Physics, J. D. Andrade (ed.), Plenum Press, New York, 1985, pp. 273-291.

20. J.S. Trent, J. I. Scheinbeim, and P. R. Couchman, "Ruthenium tetraoxide staining of polymers for electron microscopy," Macromol., 16, 589-598 (1983). 
21. D. J. Lyman, W. M. Muir, and I. J. Lee, "The effect of chemical structure and surface properties of polymers on the coagulation of blood I: Surface free energy effects," Trans. Am. Soc. Artif. Int. Org., 11, 301-306 (1965).

22. P. K. Weathersby, T. Kolobow, and E. Stool, "Relative thrombogenicity of polydimethylsiloxane and silicone rubber constituents," J. Biomed. Mater. Res., 9, 561-568 (1975).

23. D. J. Lyman and K. Knutson, "Chemical, physical, and mechanical aspects of blood compatibility," in Biomedical Polymers, E. Goldberg and A. Nakajima (eds.), Academic Press, New York, 1980, pp. 1-30.

24. W. M. Zapol, S. Bloom, A. Carvalho, T. Wonders, M. Skoskiewicz, R. Schneider, and M. Snider, "Improved platelet economy using fillerfree silicone rubber in long-term membrane lung perfusion," Trans. Am. Soc. Artif. Int. Org., 21, 587-591 (1975).

25. W. G. Yates, R. N. Schaap, and G. C. Baumann, "Effects of filler-free silicone rubber on platelets during bovine extracorporeal membrane oxygenation," Trans. Am. Soc. Artif. Int. Org., 24, 644-648 (1978).

26. E. Nyilas and E. L. Kupski, "Surface microstructural factors and blood compatibility of silicone rubber," I. Biomed. Mater. Res., 4, 369-432 (1970).

27. E. W. Salzman, J. Lindon, D. Brier, and E. W. Merrill, "Surface-induced platelet adhesion, aggregation and release," Ann. N.Y. Acad. Sci., 283, 114-127 (1977).

28. J. L. Costa and D. L. Murphy, "Platelet 5-HT uptake and release stopped rapidly by formaldehyde," Nature (London), 255, 407-408 (1975).

29. R.C. Arora and H. Y. Meltzer, "A modified assay method for determining serotonin uptake in human platelets," Clin. Chem. Acta, 112, 225233 (1981).

30. G. A. Adams and I. A. Feuerstein, "Kinetics of platelet adhesion and aggregation on protein-coated surfaces: Morphology and release from dense granules," ASAIO Y., 4, 90-99 (1982).

31. T. Okano, C. Nojiri, and D. Grainger, unpublished evidence, University of Utah.

32. L. D. Brace and J. Fareed, "An objective assessment of the interaction of heparin and its fractions on human platelets," Sem. Thromb. Haem., 11, 190-198 (1985).

33. A. S. Hoffman, T. A. Horbett, and B. D. Ratner, "Interactions of blood and blood components at hydrogel interfaces," Ann. N.Y. Acad. Sci., 283, 372-389 (1977).

34. J. L. Brash and S. J. Whicker, "Interactions of platelets with surfaces: A factorial study of adhesion and associated release of serotonin," in Artificial Organs, R. M. Kenedi (ed.), University Park Press, Baltimore, 1977, pp. 263-272.

35. D. L. Coleman, D. E. Gregonis, and J.D. Andrade, "Blood-materials interactions: The minimum interfacial free energy and the optimum polar/apolar ratio hypotheses," J. Biomed. Mater. Res., 16, 381-398 (1982).

Received December 16, 1987

Accepted September 25, 1989 